\title{
Coincident Observations of Dye and Drifter Relative Dispersion over the Inner Shelf $\mathscr{A}$
}

\author{
LEONEL ROMERO AND J. CARTER OHLMANN \\ Earth Research Institute, University of California, Santa Barbara, Santa Barbara, California \\ ENRIC PALLÀS-SANZ \\ Centro de Investigación y Educación Superior de Ensenada, Ensenada, Mexico \\ NiCHOLAS M. STATOM \\ Scripps Institution of Oceanography, University of California, San Diego, La Jolla, California \\ PAUla PÉREZ-BRUNIUS \\ Centro de Investigación y Educación Superior de Ensenada, Ensenada, Mexico \\ STÉPHANE MARITORENA \\ Earth Research Institute, University of California, Santa Barbara, Santa Barbara, California
}

(Manuscript received 26 February 2019, in final form 17 July 2019)

\begin{abstract}
Coincident Lagrangian observations of coastal circulation with surface drifters and dye tracer were collected to better understand small-scale physical processes controlling transport and dispersion over the inner shelf in the Gulf of Mexico. Patches of rhodamine dye and clusters of surface drifters at scales of $O(100) \mathrm{m}$ were deployed in a cross-shelf array within $12 \mathrm{~km}$ from the coast and tracked for up to $5 \mathrm{~h}$ with airborne and in situ observations. The airborne remote sensing system includes a hyperspectral sensor to track the evolution of dye patches and a lidar to measure directional wavenumber spectra of surface waves. Supporting in situ measurements include a CTD with a fluorometer to inform on the stratification and vertical extent of the dye and a realtime towed fluorometer for calibration of the dye concentration from hyperspectral imagery. Experiments were conducted over a wide range of conditions with surface wind speed between 3 and $10 \mathrm{~m} \mathrm{~s}^{-1}$ and varying sea states. Cross-shelf density gradients due to freshwater runoff resulted in active submesoscale flows. The airborne data allow characterization of the dominant physical processes controlling the dispersion of passive tracers such as freshwater fronts and Langmuir circulation. Langmuir circulation was identified in dye concentration maps on most sampling days except when the near surface stratification was strong. The observed relative dispersion is anisotropic with eddy diffusivities $O(1) \mathrm{m}^{2} \mathrm{~s}^{-1}$. Near-surface horizontal dispersion is largest along fronts and in conditions dominated by Langmuir circulation is larger in the crosswind direction. Surface convergence at fronts resulted in strong vertical velocities of up to $-66 \mathrm{~m} \mathrm{day}^{-1}$.
\end{abstract}

\section{Introduction}

Small-scale physical oceanographic processes at scales of $O(100)$ m or smaller are important for the transport and dispersion of tracers in the upper ocean. These

Supplemental information related to this paper is available at the Journals Online website: https://doi.org/10.1175/JPO-D-190056.s1.

Corresponding author: Leonel Romero, leromero@eri.ucsb.edu include submesoscale processes such as fronts, filaments, and eddies, Langmuir circulation, wind-driven shear, and turbulence. In coastal regions, tidal inlets and rivers can also play an important role for the transport and dispersion of tracers over the shelf (e.g., Whilden et al. 2014; Androulidakis et al. 2018). Until recently much of our knowledge about submesoscale processes came from modeling studies. The work by Capet et al. (2008a,b,c) with the Regional Ocean Modeling System (ROMS) showed the importance of submesoscale processes on the overall energy balance of the ocean, 
contributing to the forward energy cascade with a less steep wavenumber eddy kinetic energy spectrum (proportional to $k^{-2}$ ) at smaller scales. The model results show increasing current gradients with increasing resolution, exceeding the Coriolis frequency $f$ in magnitude at horizontal resolutions below $1 \mathrm{~km}$. Similarly, the vertical velocity and surface convergence at fronts were shown to increase with increased model resolution. Poje et al. (2010) conducted a series of numerical experiments on relative dispersion with ROMS to investigate the effect of model resolution. The results showed greater relative dispersion at small scales with increasing model resolution due to increased straining rates. Romero et al. (2013) characterized the horizontal dispersion over the inner continental shelf within $15 \mathrm{~km}$ from the shore with ROMS with a horizontal grid spacing from 75 to $250 \mathrm{~m}$. The results showed strong anisotropy with larger dispersion along-shelf and largest dispersion over areas dominated by submesoscale activity near headland regions. Subsequently, Romero et al. (2016) characterized the dispersion and dilution of creek runoff using ROMS with a grid spacing of $100 \mathrm{~m}$, reporting scale-dependent diffusivities consistent with Romero et al. (2013).

Several observational studies have recently investigated Lagrangian transport over a wide range of scales in deep water and coastal environments. Most studies have focused on the effects of submesoscale processes, wind forcing, and coastal rivers on Lagrangian transport and dispersion. Poje et al. (2014) presented surface drifter observations ([Grand Lagrangian Deployment (GLAD)] of Lagrangian dispersion for initial separations of $200 \mathrm{~m}$ and found good agreement with Richardson's $t^{3}$ scaling. In contrast, the reanalysis of the GLAD dataset for initial separations of $1 \mathrm{~km}$ by BeronVera and LaCasce (2016) found good agreement with nonlocal dispersion due to mesoscale straining. This is consistent with the fact that submesoscale processes are intensified at horizontal scales smaller than $1 \mathrm{~km}$, and therefore have stronger effects on the dispersion at smaller scales. D'Asaro et al. (2018) conducted a multiscale experiment of horizontal dispersion with a large array of clusters of surface drifters evenly spaced at $1 \mathrm{~km}$ and placed on the dense side of a front of a cyclonic eddy. The results showed drifter convergence and rapid dispersion along a front followed by a convergence at the center of the eddy before subsequently slowly dispersing, highlighting the importance of both local and nonlocal processes.

At smaller scales $O(100) \mathrm{m}$ or smaller large-eddy simulations (LES) are commonly used to resolve nonhydrostatic effects such as Langmuir circulation due to vortex forces (Craik and Leibovich 1976; McWilliams et al. 1997, 2004) and its interaction with surface temperature fronts (Sullivan and McWilliams 2018). Liang et al. (2018) investigated dispersion of particles with varying buoyant rising velocities showing significant dispersion effects due to Langmuir circulation at scales smaller than $100 \mathrm{~m}$. At larger scales, the dispersion was found to be significantly lower than that expected by submesoscale processes. Another LES study of dispersion under the influence of submesoscale turbulence and wind forcing without wave effects (Mensa et al. 2015) showed increased dispersion downwind with increased wind speed, as expected due to wind shear and a background turbulent diffusivity.

There are a variety of physical processes that promote relative dispersion on small scales. Theory and modeling studies tend to isolate individual processes and relate dynamics to growth rates in relative dispersion. Observationally, however, the understanding of ocean dynamics on relatively small scales is generally inferred from two-dimensional measurements of relative dispersion growth, using the links to physics identified in theory/models. Only very recently have ocean observations begun to look directly at the role of physics in dispersion and this is limited to the role of submesoscale processes. This study is concerned with the question of whether the physical processes responsible for the dispersion of tracers near the ocean surface can be identified and characterized at submesoscales $O(100) \mathrm{m}$. The work expands on past work by presenting direct observational evidence of Langmuir turbulence on relative dispersion.

We present a novel set of horizontal dispersion observations near the ocean surface with dye and surface drifters on scales of $O(100) \mathrm{m}$ at water depths between 10 and $20 \mathrm{~m}$. The work quantifies the underestimate in horizontal dispersion from fully $3 \mathrm{D}$ circulation that is inherent in the $2 \mathrm{D}$ dispersion observations typically presented. The coincident observations from 2D and 3D motions also allow the role of physics, particularly submesoscale fronts and Langmuir turbulence, forcing the dispersion to be identified and characterized. This paper is organized as follows. Section 2 describes the experimental setup and methods. The results are reported in section 3. The discussion and conclusions are described in sections 4 and 5, respectively.

\section{Experimental setup and methods}

We conducted a Lagrangian experiment over the inner shelf using surface drifters and a fluorescent dye tracer with supporting in situ and remote sensing observations. The investigation was conducted during a 2-week-long period, carrying out a total of seven daily 

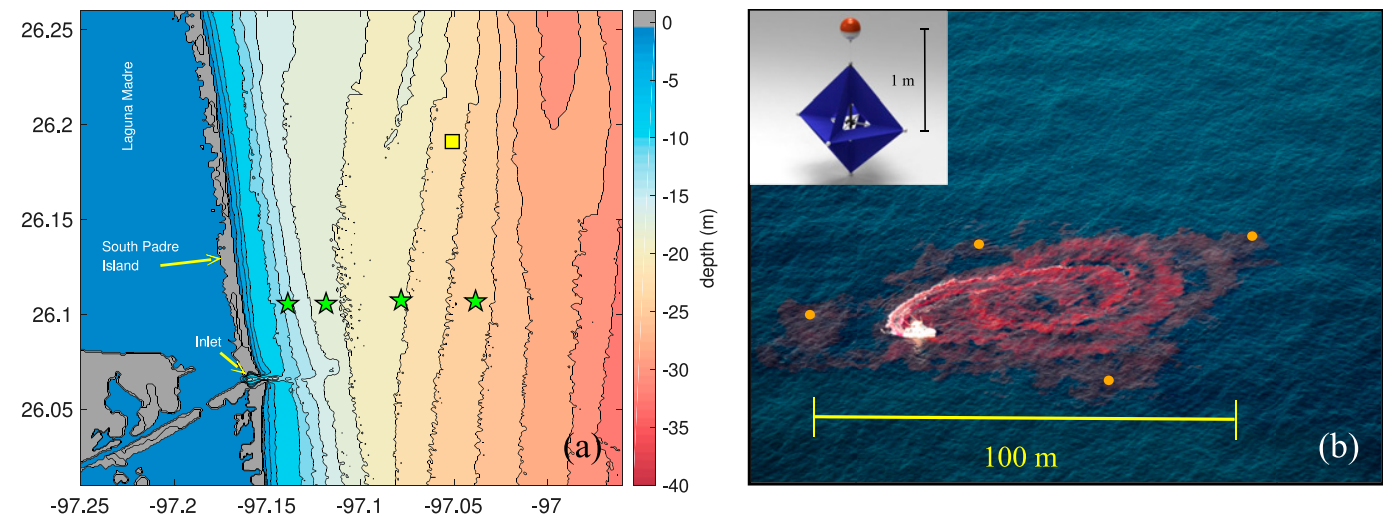

FIG. 1. (a) Study site of the experiments off the coast South Padre Island, TX. Nominal dye and drifter deployment stations 1-4 (green) are located at 2, 4, 8, and $12 \mathrm{~km}$ offshore in water depths of 10, 18, 20, and $23 \mathrm{~m}$, respectively. Stations 1-4 are roughly located $8 \mathrm{~km}$ south/southwest of NDBC buoy 42044 (yellow square) with supporting surface winds measurements. The bathymetry data shown is the 3-s product from the National Oceanic and Atmospheric Administration/National Geophysical Data Center (NOAA/NGDC) coastal relief data. (b) Dye and drifter deployment consisted of the deployment of 4 drifters (orange circles) in a cross configuration, with pair separations of $100 \mathrm{~m}$ in two orthogonal directions. The boat then proceeded to fill in the box with dye with spiraling tracks over a period of $10 \mathrm{~min}$. Sometimes the drifters and dye underwent significant deformation during the time $(10 \mathrm{~min})$ of dye deployment. The inset shows a photograph of a MicroStar drifter that was drogued at $1 \mathrm{~m}$ below the ocean surface (source: https://www.pacificgyre.com). Photo credit: Nick Statom. Drifters were colored manually for clarity.

experiments on average every other day due to weather constrains.

\section{a. Study site}

The Inner Shelf Dispersion Experiment (ISDEX) was conducted in the Gulf of Mexico, off the coast of South Padre Island, Texas, within $15 \mathrm{~km}$ from the shore (Fig. 1a). The study site was selected for its proximity to Brownsville Airport and Port Isabell, needed for airborne and boat operations, as well as its proximity to Perdido Canyon, which is an area with priority for deep-water oil exploration. The coastal circulation in the region is influenced by two modes of wind variability (Moeller et al. 1993, downwelling and upwelling), surface waves with relatively short peak periods (Appendini et al. 2014), as well as density and momentum variations due to water exchanges through Brazos Island Harbor Inlet connecting nearshore waters with the Laguna Madre behind the barrier island.

Nominal dye and drifter deployments (stations 1-4) are located at 2, 4, 8, and $12 \mathrm{~km}$ offshore in water depths of $10,18,20$, and $23 \mathrm{~m}$, respectively (Fig. 1a). Stations 1-4 are roughly located $8 \mathrm{~km}$ south/southwest of NDBC buoy 42044 with supporting surface wind measurements (Fig. 1a). Deployments each day typically started at station 1 and continued sequentially with stations $2-4$. Not all four stations were seeded with dye and drifters each sampling day due to weather considerations. Similarly, exact locations of the stations were occasionally adjusted due to environmental conditions for safe navigation and sampling considerations depending on the mean current direction, cloud coverage, and sea state. The airborne sampling was not possible with low-level clouds or strong sun glitter around midday, which posed a big challenge for the field operations. To minimize the unwanted effects of sun glitter on the airborne remote sensing imagery, field operations started as early as possible (weather dependent). Therefore, deployments were not repeated at the same tidal phase on different days. On 6 June, stations 3 and 4 were moved inshore to 6 and $8 \mathrm{~km}$ from the shore, respectively, due to the clouds offshore. This decision was made during the course of the experiment therefore station 4 ended up being deployed before station 3 .

\section{b. Instrumentation}

The instrumentation was composed of in situ and remote sensors. Instrumentation on board the F/V Salt Walker included 16 reusable Microstar surface drifters, a 4-Hz conductivity-temperature-depth (CTD) profiler (SeaBird 19 plus v2) with a $1-\mathrm{Hz}$ rhodamine dye fluorometer (Wet Laboratories ECO), a towed deployment body (C-ray) with fluorometers (Turner designs C3), and a GPS. The F/V Salt Walker also carried a mixing pump with a flowmeter attached to a 270 -gallon tank and an in-house-built diffuser. The diffuser consisted of two rods $2.5 \mathrm{~m}$ long with $5.5-\mathrm{mm}$ fluid ports drilled at even spacing with a handle and a hose connector to the pump. 
The C3 fluorometer on the C-ray has three channels (rhodamine, chlorophyll, and turbidity) as well as pressure and temperature sensors allowing the collection of horizontal profiling measurements at constant depth with real-time capability. The CTD temperature, conductivity, and pressure sensors were calibrated by the manufacture. The CTD and C-ray fluorometers were calibrated in-house against known dye concentration samples in the range of 20-140 ppb. Both instruments were calibrated in fresh clear water with an accuracy greater than $2 \%$. Despite the calibration, the CTD fluorometer data did not go to zero in the absence of dye. This was corrected during postprocessing by subtracting $1 \mathrm{ppb}$ from all the casts.

Microstar drifters have a GPS on board for tracking and a drogue centered at $1 \mathrm{~m}$ below the ocean surface (Ohlmann et al. 2005). Drifter data transmission is in near-real time every $10 \mathrm{~min}$ with position uncertainties of about $\sim 2 \mathrm{~m}$. The 10-min sampling frequency provides a high signal-to-noise ratio even in low-velocity regimes. The spatial accuracy and near-real-time transmission enable drifters to be recovered and redeployed. The drifters use a collapsible scaled-down tristar type drogue with a drag-area-ratio greater than 41 . Slip is $\sim 0.1 \%$ of the wind speed $\left(\sim 1 \mathrm{~cm} \mathrm{~s}^{-1}\right.$ in $10 \mathrm{~m} \mathrm{~s}^{-1}$ of wind), which is typical of modern-day drifters (Niiler et al. 1995).

The instrumentation on board the Aspen Helicopters Partenavia Observer (P68-OBS) aircraft was the Modular Aerial Sensing System (MASS; Melville et al. 2016) composed of a longwave infrared camera (QWIP-FLIR SC6000), a high-resolution visible camera (JaiPulnix AB800CL), a hyperspectral sensor (Specim Eagle AISA), a scanning lidar (Riegl Q680i), and an inertial measurement unit (IMU) with GPS (Novatel SPAN-LN200). Supporting surface winds measurements were available from NDBC buoy 42044 located $8 \mathrm{~km}$ north-northeast of the study area. Also, offshore wave observations were available from NDBC buoy 42020 located roughly $90 \mathrm{~km}$ to the northeast and were particularly valuable for planning ship operations during the field experiments.

\section{c. Dye and drifter deployment}

Rhodamine-WT is a fluorescent dye tracer suitable for applications near the ocean surface because of its relatively low degradation due to sunlight exposure and is considered harmless at concentrations below $370 \mathrm{ppb}$. The dye is heavier than the water, therefore it was combined with isopropyl alcohol and seawater to achieve neutral buoyancy. Given a volume of dye $V_{d}$, the volume of alcohol $V_{a}=V_{d}\left(S_{g r}-S_{g \mathrm{sw}}\right) /\left(S_{g \mathrm{sw}}-S_{g a}\right)$, where $S_{g r}=1.1328$ and $S_{g a}=0.7832$ are the specific gravity of rhodamine, and $99 \%$ isopropyl alcohol at $25^{\circ} \mathrm{C}$, respectively, and $S_{\text {gsw }}$ is the specific gravity of seawater. For one dye patch, $3.8 \mathrm{~L}$ of $20 \%$ RhodamineWT dye were combined with $1.9 \mathrm{~L}$ of isopropyl alcohol that was then mixed in a tank with $175 \mathrm{~L}$ of seawater pumped and mixed on the boat matching the seawater density to within an accuracy of $0.1 \mathrm{~kg} \mathrm{~m}^{-3}$ with an initial dye mixture concentration inside the tank of $4.2 \times 10^{6} \mathrm{ppb}$ or $0.4 \%$.

The mixture of dye-alcohol-seawater for all the patches to be deployed in a day was made at the first dye release station. Therefore, the density of the mixture inside the tank did not necessarily exactly match that in the ocean at stations 2-4. However, as shown below, the dye mixture was diluted by a factor of $2 \times 10^{-6}$ during deployment with in situ measured concentrations of about $5 \mathrm{ppb}$ immediately after deployment, and the density errors are of order $1 \times 10^{-7} \%$. We deployed four dye patches on 31 May, 3 June, and 6 June when the weather allowed. On 26 May, we only did a deployment at station 1. On 29 May and 1 June deployments were made at stations $1-3$. On the last day, 8 June, two deployments were carried out with a much larger initial diameter of $500 \mathrm{~m}$. The 8 June observations are excluded from the analysis because of the larger spatial scale targeted.

The typical deployment of both drifters and dye started with a set of four drifters deployed in a "cross" configuration with a spacing of $100 \mathrm{~m}$ in each orthogonal direction (Fig. 1b). The drifters provide a set of markers that can be used for subsequent deployment of the dye. Once the drifters were in place the dye solution was deployed in two roughly 2.5 -m-wide swaths from the stern of the boat, with roughly 2-m separation between swaths (Fig. 1b). Dye was injected at the ocean surface at a flow rate of $18 \mathrm{~L} \mathrm{~min}^{-1}$ from the boat moving at roughly $4 \mathrm{~m} \mathrm{~s}^{-1}$. The boat moved in a roughly circular pattern about the four drifters and spiraled inward to complete a deployment of a "circular" patch of dye with roughly $100 \mathrm{~m}$ diameter (Fig. 1b) over a period of $10 \mathrm{~min}$. The 2-m-long section between dye injection swaths was quickly filled in by small-scale turbulence that was greatly enhanced by the boat's wake, which also helped mix the dye vertically. Immediately after deployment, the dye reached on average 3.5-m depth with mean concentration values of $5 \mathrm{ppb}$, consistent with the dye budget calculations. Sometimes the drifters and dye underwent significant deformation during the time (10 mins) of dye deployment (e.g., Fig. 1b). This was accounted for in the dispersion analysis by referencing the dispersion relative to the time of drifter deployment.

\section{d. Sampling strategy}

Here we describe the sampling strategy with in situ and remote sensing instrumentation. Shortly after 
deployment of each dye patch, the boat would then position itself at the center of the patch to collect a CTD vertical profile. The boat would then deploy the tow body (C-ray) to profile the dye horizontally at $1 \mathrm{~m}$ below the surface, moving at a speed of $1 \mathrm{~m} \mathrm{~s}^{-1}$, as the boat traveled out the patch providing reference in situ measurements for calibration of the remote sensing observations. The vertical CTD profiles were collected after a 2-min surface "soak" at a descent rate of roughly $1 \mathrm{~m} \mathrm{~s}^{-1}$ to a depth of up to $20 \mathrm{~m}$. For the analysis, only downcasts are considered because upcasts are affected by the wake of the instrument. Seawater properties of salinity and density were derived using the recommended sequence of Sea-Bird's SeaSoft software modules and settings (Sea-Bird 2017; www.seabird.com/software).

After deploying the last dye patch, the boat would sample the spatial structure of the patch in two orthogonal directions with the C-ray at $1 \mathrm{~m}$ below the surface a few times, supplemented with occasional CTD vertical casts near the center of the patch. Horizontal orthogonal dye profiling was repeated whenever possible toward the end of the day during the recovery of the drifters. In other words, orthogonal transects through the dye patches were only done at the last station of the day and a few instances during the recovery of the drifters. It was not always possible to sample the dye during the recovery of the drifters due to weather and also because the dye was not always visible toward the end of the day.

Airborne sampling was constrained by the weather and low-level cloud coverage but typically started during, or just after, deployment of the first dye patch. The aircraft sampled the dye patches for up to $4 \mathrm{~h}$, providing several snapshots per hour of each dye patch, roughly every 5-10 min. A typical flight overpass collected infrared imagery to detect flow structures, such as fronts and eddies, hyperspectral data to measure the dye evolution, visible imagery to detect the dye patches, and lidar data to measure the wave field.

\section{e. Dye concentration calibration}

The hyperspectral imager measures the water-emitting spectral radiance, which can be used to detect dye in the water as described below. The sensor operates in a push-broom mode measuring radiance at wavelengths between 400 and $990 \mathrm{~nm}$, with a $1.25-\mathrm{nm}$ spectral resolution and a 944-pixel swath resolution. For the nominal aircraft flying altitudes between 300 and $1500 \mathrm{~m}$ above mean sea level during the experiment, the swath widths vary between 200 and $950 \mathrm{~m}$ with cross-track resolutions between 0.2 and $1 \mathrm{~m}$, respectively. The alongtrack resolution was kept constant at $0.6 \mathrm{~m}$, which is determined by the ratio of the aircraft speed $\left(50 \mathrm{~m} \mathrm{~s}^{-1}\right)$ to the sampling rate $(80 \mathrm{~Hz})$.
Rhodamine WT is a fluorescent dye with peak absorption (or excitation) and emission bands at 558 and $582 \mathrm{~nm}$ (Wilson et al. 1968). The ratio of the spectral radiance within the absorption and emission bands measured by the hyperspectral sensor can be used to infer the dye concentration with a linear relationship at low concentration values; at high concentrations the relationship becomes nonlinear (Clark et al. 2014). We used band-averaged radiances from 546 to $560 \mathrm{~nm}\left(L_{\mathrm{ex}}\right)$ and from 588 to $602 \mathrm{~nm}\left(L_{\mathrm{em}}\right)$, for the absorption and emission bands, respectively. These ranges are chosen because they give a stronger signal for the ratio $L_{\mathrm{em}} / L_{\mathrm{ex}}$ due to dye fluorescence (Clark et al. 2014).

The hyperspectral imagery collected around midday was affected by sun glitter as can be seen in the RGB image and ratio $L_{\mathrm{em}} / L_{\mathrm{ex}}$ over a dye patch in Figs. 2a and 2c, respectively. Following Hedley et al. (2005), the radiances within the visible spectrum can be corrected from sun glitter using the radiance at near-infrared wavelengths using a linear relationship. For this, we chose a data swath collected on 3 June 2016, in conditions with strong sun glitter. Figure 3 a shows the radiance at the excitation band $L_{\text {ex }}$ against that at the near-infrared $L_{\text {nir }}$ at $788.61 \mathrm{~nm}$ for that data. The best-fit $L_{\mathrm{ex}}=0.34+1.457$ $L_{\text {nir }}$ is shown with a black line, and that for the emission band $L_{\mathrm{em}}=0.01+1.421 L_{\mathrm{nir}}$ (not shown). Similarly, the red $\left(L_{r}\right)$, green $\left(L_{g}\right)$, and blue $\left(L_{b}\right)$ radiances against the near-infrared yield best fits:

$$
\begin{aligned}
& L_{r}=-0.09+1.459 L_{\text {nir }}, \\
& L_{g}=0.282+1.457 L_{\text {nir }}, \quad \text { and } \\
& L_{b}=-0.78+1.047 L_{\text {nir }} .
\end{aligned}
$$

The best-fit scaling factors are then used to correct radiances according to

$$
L_{i}^{\prime}=L_{i}-b_{i}\left[L_{\mathrm{nir}}-\min \left(L_{\mathrm{nir}}\right)\right],
$$

where $L_{i}$ is the measured radiance at the $i$ th wavelength, $b_{i}$ is the scaling factor from the best-fit against $L_{\text {nir }}$ and $\min \left(L_{\text {nir }}\right)$ is the minimum near-infrared radiance. We used $\min \left(L_{\text {nir }}\right)=0.045 \mathrm{~mW} \mathrm{~cm}^{-2} \mathrm{sr}^{-1} \mu \mathrm{m}^{-1}$ corresponding to the mean minimum value from all days. Figures $2 b$ and $2 d$ show the results after removal of the sun glitter from true color and the ratio $L_{\mathrm{em}} / L_{\mathrm{ex}}$, respectively. The glitter is largely eliminated increasing the signal-to-noise ratio and improving the detection ability of evolving dye patches. However, as the glitter becomes too intense and the dye concentration decreases the glitter correction is not effective and that data become too noisy to be used for the analysis. 


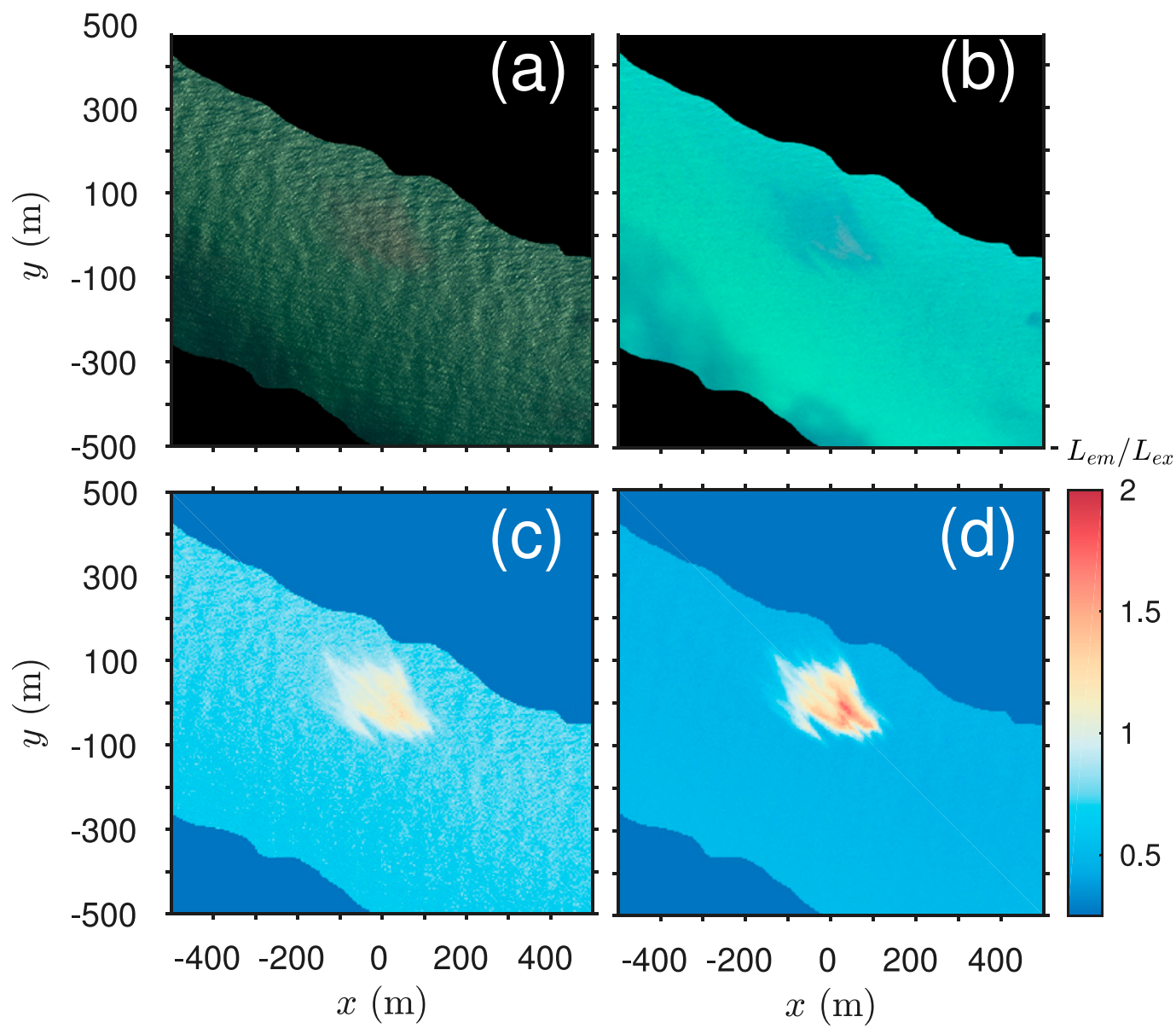

FIG. 2. (a),(b) True-color hyperspectral imagery and (c),(d) ratio of the radiance at the emission to the excitation bands of rhodamine dye $L_{\mathrm{em}} / L_{\mathrm{ex}}$. Images shown (left) before and (right) after correcting for sun glitter according to Eqs. (1)-(4). Data were collected at 1505 UTC 6 Jun 2016, in conditions with relatively low sun glitter. The dark areas along the swath (i.e., lower left corner) of the true-color data are due to clouds, which are not detectable in $L_{\mathrm{em}} / L_{\mathrm{ex}}$.

After applying the sun glitter corrections, the dye concentration $C(x, y)$ was calibrated using the ratio $L_{\mathrm{em}} / L_{\mathrm{ex}}$ against in situ dye concentration measurements assuming a linear relationship. The data calibration was carried out using observations from the towed fluorometer (C-ray). CTD data with limited spatial coverage were used to inform on the vertical extent of the dye. Figure $3 \mathrm{~b}$ shows a scatter diagram of collocated in situ dye concentration and the coincidently remotely sensed ratio $L_{\mathrm{em}} / L_{\mathrm{ex}}$, where the color indicates the number of observations within the bin. The linear best fit is shown with a black line. Dye concentrations $C_{V}$ in ppb were scaled to vertically integrated values $C$ in milligrams per square meter $\left(\mathrm{mg} \mathrm{m}^{-2}\right)$ using a vertical length scale of the dye concentration $z_{C}$ from the CTD data. The vertical scale $z_{C}=\int z C(z) d z / \int C(z) d z$ was obtained for all patches soon after deployment, except for 26 May due to an issue with the CTD pressure sensor. The overall mean value is $\left\langle z_{C}\right\rangle=3.65 \pm 0.5 \mathrm{~m}$ (Fig. $4 \mathrm{~d}$ ).

In situ measurements collected with the C-ray were corrected for water temperature differences, however the ratio $L_{\mathrm{em}} / L_{\mathrm{ex}}$ is also affected by temperature. Therefore, the data were binned by surface temperature $25.2^{\circ} \pm 0.5^{\circ}$ and $27.5^{\circ} \pm 0.3^{\circ} \mathrm{C}$ yielding the best fits:

$$
C=13.75 L_{\mathrm{em}} / L_{\mathrm{ex}}-5.75
$$

and

$$
C=16.25 L_{\mathrm{em}} / L_{\mathrm{ex}}-6.03,
$$

respectively, with $C$ in milligrams per square meter. Equations (5) and (6) were used to calibrate the entire hyperspectral dataset. Examples of dye concentration images of a dye patch 56 and 92 min after deployment are shown in Figs. 3c and 3d, respectively. The maximum 

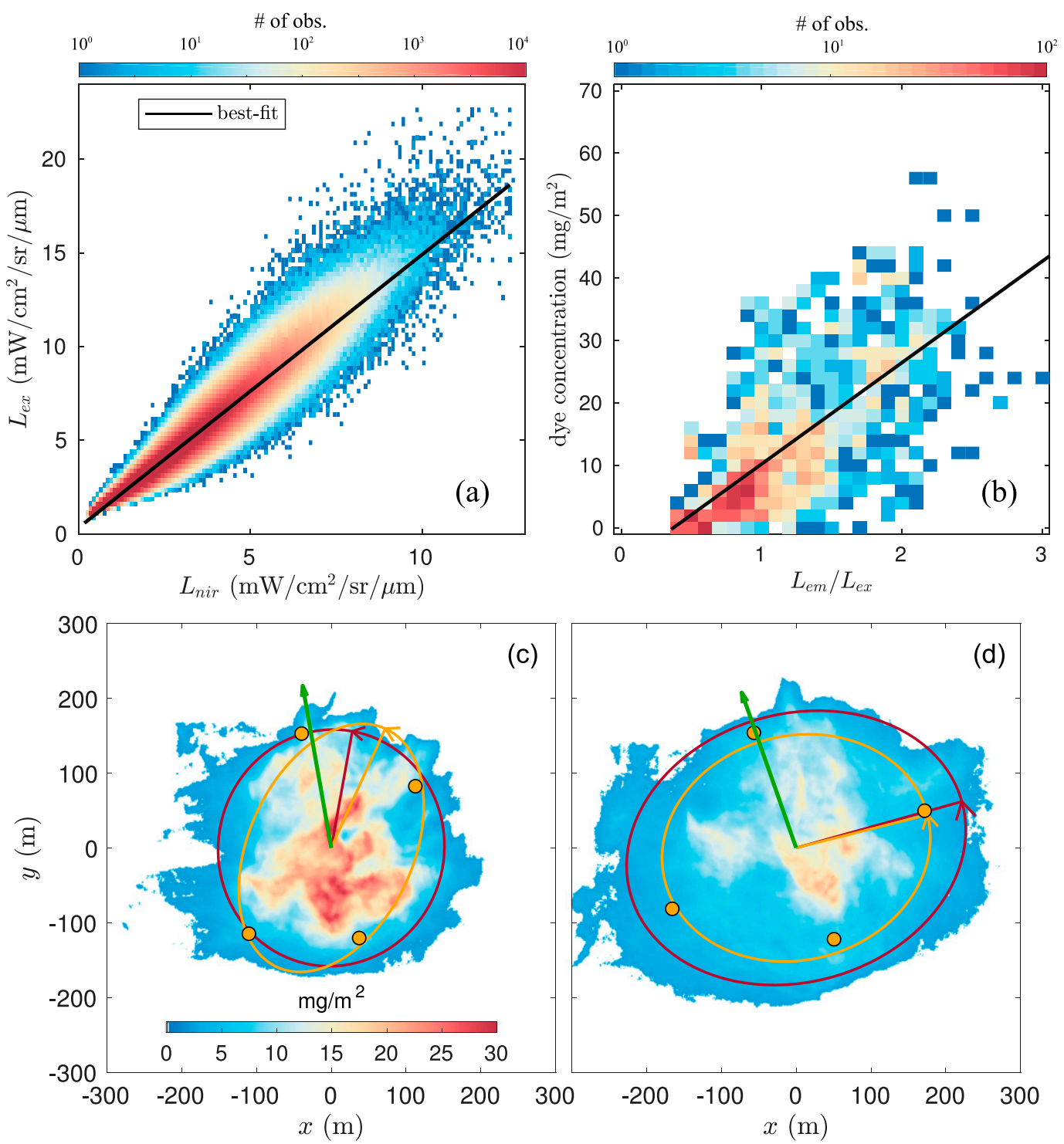

FIG. 3. (a) Spectral radiance within the excitation band $L_{\mathrm{ex}}$ against the radiance at the near-infrared band $L_{\text {nir }}$. (b) Scatter diagram of depth integrated dye concentration measurements and the ratio of the emission $L_{\mathrm{em}}$ and excitation $L_{\mathrm{ex}}$ bands of Rhodamine-WT dye measured by the hyperspectral sensor. The black lines show linear best fits. (c),(d) Example of a dye patch with an overlapping cluster of drifters (orange circles) deployed at station 2 on 3 Jun 2016, with relatively weak winds $\left(4 \mathrm{~m} \mathrm{~s}^{-1}\right)$. The time interval between (b) and (c) is 36 min. Data are plotted with respect to the centroid at $(0,0)$. Gray and orange dispersion ellipses indicate the root-mean-square widths $\left(R_{1}, R_{2}\right)$ and orientation of the principal components (straight lines) for the dye and drifter data, respectively. Green arrows show the wind direction.

concentration decreased from 30 to $20 \mathrm{mg} \mathrm{m}^{-2}$ during the 36 min between images.

The remote sensing observations of depth-integrated rhodamine dye patches are limited by the spectral light attenuation in water. The diffuse attenuation coefficient at $490 \mathrm{~nm}\left(K_{490}\right)$ estimated from the relative water-emitting radiances at 490 and $555 \mathrm{~nm}$ is a good general indicator of water clarity (Mueller 2000), and can be used to estimate attenuation coefficients at other wavelengths (Austin and Petzold 1986; refer to the online supplemental material). The values of $K_{490}$ throughout the experiment vary between 0.05 and $0.38 \mathrm{~m}^{-1}$ for the clearest and more turbid waters, with corresponding average optical depths for the excitation band of 12.1 and $4 \mathrm{~m}$, and for the emission band between 4.8 and $2.7 \mathrm{~m}$, respectively. Therefore, the optical depth of the ratio $L_{\mathrm{em}} / L_{\mathrm{ex}}$ is limited by the emission band. The mean values of the optical depth at the emission 

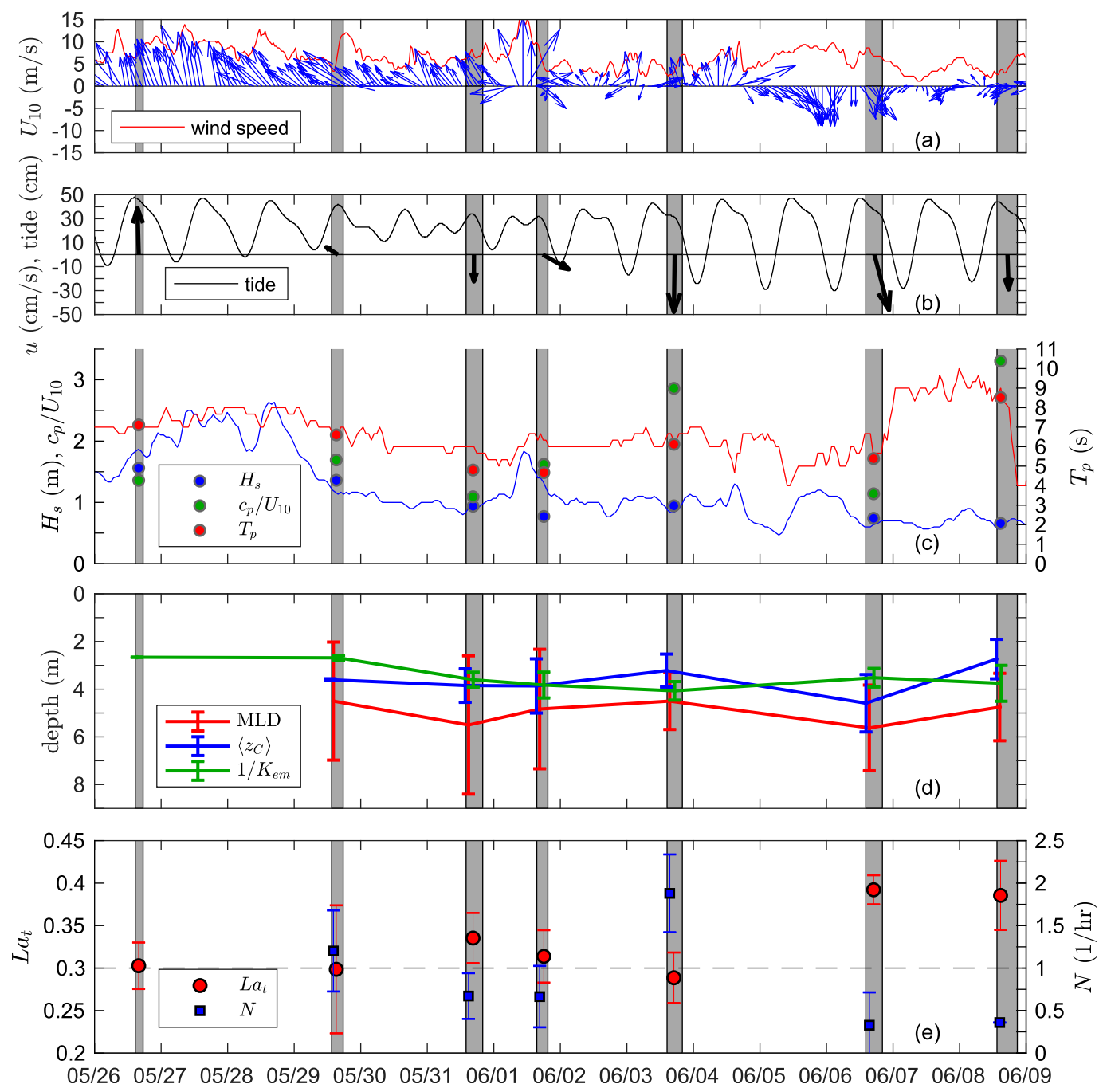

FIG. 4. (a) Wind speed $U_{10}$ and direction from NDBC buoy 42044. (b) Mean surface currents u measured by the drifters and tides measured at South Padre Island (NOAA station 8779750). (c) Significant wave height $H_{s}$, wave age $c_{p} / U_{10}$, and peak period $T_{p}$ measured by the lidar. The corresponding offshore buoy wave observations of $H_{s}$ and $T_{p}$ are shown with solid blue and red lines, respectively. (d) Mixed layer depth (MLD; red line), initial mean depth of dye patches (blue line), and optical depth at the emission band $\left(1 / K_{\mathrm{em}}\right)$ (green line). (e) Turbulent Langmuir number $\left(\mathrm{La}_{t}\right)$ calculated from the lidar and wind data and mean near surface buoyancy frequency $\bar{N}$. The horizontal dashed line shows $\mathrm{La}_{t}=0.3$, consistent with that for wind-wave equilibrium. The gray vertical bars indicate the seven sampling periods.

band $\left(1 / K_{\mathrm{em}}\right)$ are shown in (Fig. $\left.4 \mathrm{~d}\right)$, with values between 2.7 and $3.8 \mathrm{~m}$, which are comparable to mean depth of dye penetration $z_{C}$, except for 29 May due to runoff. Also, the remote dye observations on that day were very limited due to low-level cloud coverage.

\section{f. Relative dispersion and diffusivity}

This subsection introduces the methods used to analyze and compare the dye and drifter data. The Lagrangian evolution of a dye patch can be quantified through principal component analysis of depth-integrated concentration $C(\mathbf{x}, t)$. Similarly, for a cluster of $N$ drifters with positions $\mathbf{x}_{j}(t)$ with $j=1, \ldots, N, C(\mathbf{x}, t)=\delta\left[\mathbf{x}-\mathbf{x}_{j}(t)\right]$, where $\delta$ is the Dirac delta function such that $C$ equals to 1 at the drifter locations and zero elsewhere. The mean position and variance of a dye patch can be characterized through moments of $C(\mathbf{x}, t)$.

The mean Lagrangian position of a tracer $\overline{\mathbf{x}}=(\bar{x}, \bar{y})$ in the zonal and meridional direction, respectively, is given by

$$
\overline{\mathbf{x}}(t)=\frac{\iint \mathbf{x} C(\mathbf{x}, t) d x d y}{\iint C(\mathbf{x}, t) d x d y},
$$


where $\overline{()}$ defines the averaging operator. Similarly, the variances in the $x$ and $y$ direction are

$$
\begin{aligned}
\sigma_{x}^{2}(t) & =\overline{[x(t)-\bar{x}(t)]^{2}} \quad \text { and } \\
\sigma_{y}^{2}(t) & =\overline{[y(t)-\bar{y}(t)]^{2}},
\end{aligned}
$$

respectively, with covariance

$$
\sigma_{x y}(t)=\overline{[x(t)-\bar{x}(t)][y(t)-\bar{y}(t)]},
$$

and total variance

$$
\sigma^{2}(t)=\sigma_{x}^{2}(t)+\sigma_{y}^{2}(t) .
$$

In a principal component coordinate system, the major and minor variances are given by

$$
\sigma_{1}^{2}(t)=\frac{1}{2}\left\{\sigma_{x}^{2}(t)+\sigma_{y}^{2}(t)+\sqrt{\left[\sigma_{x}^{2}(t)-\sigma_{y}^{2}(t)\right]^{2}+4 \sigma_{x y}(t)^{2}}\right\}
$$

and

$$
\sigma_{2}^{2}(t)=\frac{1}{2}\left\{\sigma_{x}^{2}(t)+\sigma_{y}^{2}(t)-\sqrt{\left[\sigma_{x}^{2}(t)-\sigma_{y}^{2}(t)\right]^{2}+4 \sigma_{x y}(t)^{2}}\right\},
$$

with orientation $\theta(t)=0.5 \tan ^{-1}\left\{2 \sigma_{x y}(t) /\left[\sigma_{x}^{2}(t)-\sigma_{y}^{2}(t)\right]\right\}$ (Emery and Thomson 2001).

By definition, the spatial variance of a continuous patch of tracer (i.e., dye) does not match the variance of a set of discrete points around the perimeter of the patch (i.e., drifters). Therefore, in order to properly compare the dispersion from dye patches and clusters of drifters, we introduce a factor $\gamma$ such that the dispersion $R_{i}^{2}=\gamma \sigma_{i}^{2}$ with $\gamma=4$ for the dye (i.e., two standard deviations) and $\gamma=2$ for the drifter ${ }^{1}$ data (see e.g., Figs. 3c,d), with $R^{2}=R_{x}^{2}+R_{y}^{2}=R_{1}^{2}+R_{2}^{2}$. More specifically, the $\gamma$ values come from comparing idealized variance calculations for a tracer distributed uniformly throughout a circle and uniformly about the perimeter of the circle. Example dispersion ellipses from dye and drifters illustrate the necessity of the gamma parameter (Figs. 3c,d). The dispersion ellipses for the drifters computed with $\gamma=2$ trace the positions of the drifters very well. Without the proper $\gamma$ factor that would not be the case. Finally, the mean Lagrangian current $\mathbf{u}(t)=d \overline{\mathbf{x}}(t) / d t$ and the relative diffusivity $\kappa=(1 / 2)\left(d R^{2} / d t\right)$.

\footnotetext{
${ }^{1}$ Note that gamma $=3 / 2$ for the unbiased variance definition of the drifters instead of the biased in Eq. (8).
}

\section{g. Differential kinematic properties}

The use of clusters of drifters allows for the estimation of the current gradients. For a cluster of $M$ drifters, the current gradients can be calculated through a Taylor approximation about the centroid of the drifters according to

$$
\begin{aligned}
& u_{j}(t)=\bar{u}(t)+u_{x}(t) \Delta X_{j}(t)+u_{y}(t) \Delta Y_{j}(t), \\
& v_{j}(t)=\bar{v}(t)+v_{x}(t) \Delta X_{j}(t)+v_{y}(t) \Delta Y_{j}(t),
\end{aligned}
$$

where $\mathbf{u}_{j}(t)$ are the individual drifter velocities, and $\Delta \mathbf{X}_{j}(t)=\mathbf{x}_{j}(t)-\overline{\mathbf{x}(t)}$ are the positions relative to the centroid. The current gradients $\left(u_{x}, u_{y}, v_{x}, v_{y}\right)$, where subscripts $x$ and $y$ correspond to zonal and meridional partial derivatives, respectively, can be obtained from the above equations through least squares fitting for a cluster of three or more drifters (Molinari and Kirwan 1975; Okubo and Ebbesmeyer 1976). As discussed by Ohlmann et al. (2017), the current gradient errors are reasonable provided that the cluster is not significantly deformed.

\section{h. Wave data processing}

Here we describe the postprocessing of the lidar data to obtain directional wavenumber spectra and related wave parameters [e.g., significant wave height $H_{s}$, Stokes drift $U_{s}(z)$, etc.]. The processing of the lidar data is based on the work by Romero and Melville (2010) and Romero et al. (2017). The scanning lidar (Riegl Q680i) onboard the Partenavia aircraft has a maximum sampling frequency of $400 \mathrm{KHz}$ and crosstrack raster line scans with $60^{\circ}$ swath widths $\left( \pm 30^{\circ}\right.$ from nadir) and frequencies of up to $200 \mathrm{~Hz}$ with a vertical rms error of $2 \mathrm{~cm}$. The data were collected at altitudes between 300 and $1500 \mathrm{~m}$ above mean sea level, corresponding to ground swath widths $(\sim h / 2)$ of 150 and $750 \mathrm{~m}$, respectively. For the nominal aircraft ground speed of $50 \mathrm{~m} \mathrm{~s}^{-1}$ and scanning frequencies between 70 and $150 \mathrm{~Hz}$, the along track resolution varied between 0.35 and $0.7 \mathrm{~m}$. The sampling frequency varied between 250 and $400 \mathrm{kHz}$. The scanning and sampling frequency were adjusted according to the flight altitude to maintain approximately the same resolution in along- and cross-track directions.

Raw data files were inspected visually keeping only relatively straight segments (excluding bank turns). Clean segments were divided into 2.5 -km-long sections with $50 \%$ overlap. Each $2.5-\mathrm{km}$ data section was binned on a regular horizontal grid with spacing between 0.5 and $1.5 \mathrm{~m}$, depending on the altitude. Grid points with missing data were filled in through linear interpolation. Since the cross-track raster scan of the lidar 
results in a higher density of backscattered data points toward the center (more nadir) portion of the swath, directional wavenumber spectra were calculated with the FFT's using the entire swath as well as a narrow swath reduced by $40 \%$. The narrow swath was then used to compute spectral energy at the higher frequencies and the wider swath for the spectral energy at lower frequencies. Both spectra were then combined with a ramp function resulting in a composite spectrum providing better directional resolution for the longer waves and a better resolved spectral tail. All spectra are corrected by the Doppler shift induced by the relative motion between the aircraft and the waves. The Doppler-shifted energy spectra are then binned on a polar spectral grid with a directional resolution of $5^{\circ}$, and logarithmic wavenumber resolution of $\Delta k / k=0.1236$. The ambiguous quadrants of the directional wavenumber spectra were eliminated using the local direction of the wind and the principal direction of swell propagation (i.e., toward the shore), allowing the separation of wind sea from the swell.

Average wavenumber spectra were computed every $30 \mathrm{~min}$ over the predefined dye deployment stations through the course of each experiment. The directional wavenumber spectrum $F(\mathbf{k})$ is defined such that

$$
\left\langle\eta^{2}\right\rangle=\int F(\mathbf{k}) d \mathbf{k},
$$

where $\left\langle\eta^{2}\right\rangle$ is the variance of the sea surface elevation. Following Kenyon (1970), Stokes drift profiles $U_{s}(z)$ were calculated from the wave spectra according to

$$
\mathbf{U}_{s}(z)=2 g \int F(\mathbf{k}) \frac{\mathbf{k}}{\omega(k)} \frac{k \cosh 2 k(z+h)}{\sinh 2 k h} d \mathbf{k},
$$

where $\omega(k)=\sqrt{g k \tanh k h}$ is the linear dispersion relationship, and $h$ is water depth. Contribution of the unresolved waves was approximated assuming a saturated spectrum with isotropic directional distribution within $90^{\circ}$ from the local wind (Romero and Melville 2010; Romero et al. 2012).

The Stokes drift is important not only for the advection of tracers near the ocean surface but also plays an important role on the turbulence and mixing of the upper ocean due to the Craik-Leibovich vortex force (Craik and Leibovich 1976). A measure of the waveinduced turbulence due to Langmuir circulation is the turbulent Langmuir number $\mathrm{La}_{t}=\sqrt{u_{w}^{*} / U_{s}(z=0)}$, where $u_{w}^{*}$ is the water-side friction velocity, and $U_{s}(z=0)$ is the Stokes drift at the ocean surface (McWilliams et al. 1997). The air-side friction velocity $u^{*}$ was calculated from the NDBC winds (station 42044) corrected to $10 \mathrm{~m}\left(U_{10}\right)$ using the drag coefficient by Large and Pond (1982), and converted to water-side friction velocity $u_{w}^{*}=u^{*} \sqrt{\rho_{a} / \rho_{w}}$, where $\rho_{w}$ and $\rho_{a}$ are the water and air densities, respectively.

\section{Results}

The results section is divided in three subsections: an overview of the environmental conditions during ISDEX, a bulk dispersion analysis as is commonly done in dispersion studies (e.g., LaCasce and Ohlmann 2003; Ohlmann et al. 2012; Berta et al. 2016), and a detailed chronological analysis of specific cases characterizing the physical processes driving the dispersion.

\section{a. Environmental conditions}

The wind during the experiment varied with two principal modes, northward and southward (Fig. 4a). On 26, 29, and 31 May, the winds were relatively steady blowing to the northwest with magnitudes between 6 and $12 \mathrm{~m} \mathrm{~s}^{-1}$, followed by variable winds on 1 June. On 3 June winds had a magnitude of about $5 \mathrm{~m} \mathrm{~s}^{-1}$ toward the northwest, reversing to the south by 6 June with a speed of $8 \mathrm{~m} \mathrm{~s}^{-1}$. Finally, wind blew to the southwest with increasing speed from 3 to $6 \mathrm{~m} \mathrm{~s}^{-1}$ on 8 June. The mean Lagrangian currents were initially strong to the north on 26 May and by 29 May the currents had weakened, reversing toward the south-southeast for the remainder of the experiment reaching magnitudes of up to $48 \mathrm{~cm} \mathrm{~s}^{-1}$ (Fig. $4 \mathrm{~b}$ ).

The average mixed layer depth (MLD) computed at the dye release locations is relatively shallow between 4.5 and $5.5 \mathrm{~m}$, being shallowest on 29 May and 3 June (Fig. 4d) due to increased near surface stratification (Fig. 4e) from rain and runoff . The MLD was calculated from density profiles according to Huang et al. (2018), which defines the MLD as the depth at which the relative standard deviation from the surface to a given depth is smallest. The near surface Brunt-Väisälä or buoyancy frequency

$$
N=\left(-\frac{g}{\rho_{o}} \frac{\partial \rho}{\partial z}\right)^{1 / 2}
$$

was calculated using a linear regression for $\min (-6 \mathrm{~m},-\mathrm{MLD})<z<-1 \mathrm{~m}$. This range of depths avoids the CTD noise close to the surface and consistently gives $\partial \rho / \partial z<0$ and therefore only real values of $N$.

Surface waves varied with significant heights between 0.6 and $1.5 \mathrm{~m}$ and peak periods between 4 and $8 \mathrm{~s} \mathrm{(Fig.} \mathrm{4c),} \mathrm{generally} \mathrm{toward} \mathrm{the} \mathrm{northwest,} \mathrm{with}$ occasional crossing wind sea and swell (e.g., 6 June; Figs. 4a,c). The wave age $c_{p} / U_{10}$, where $c_{p}$ is the phase 

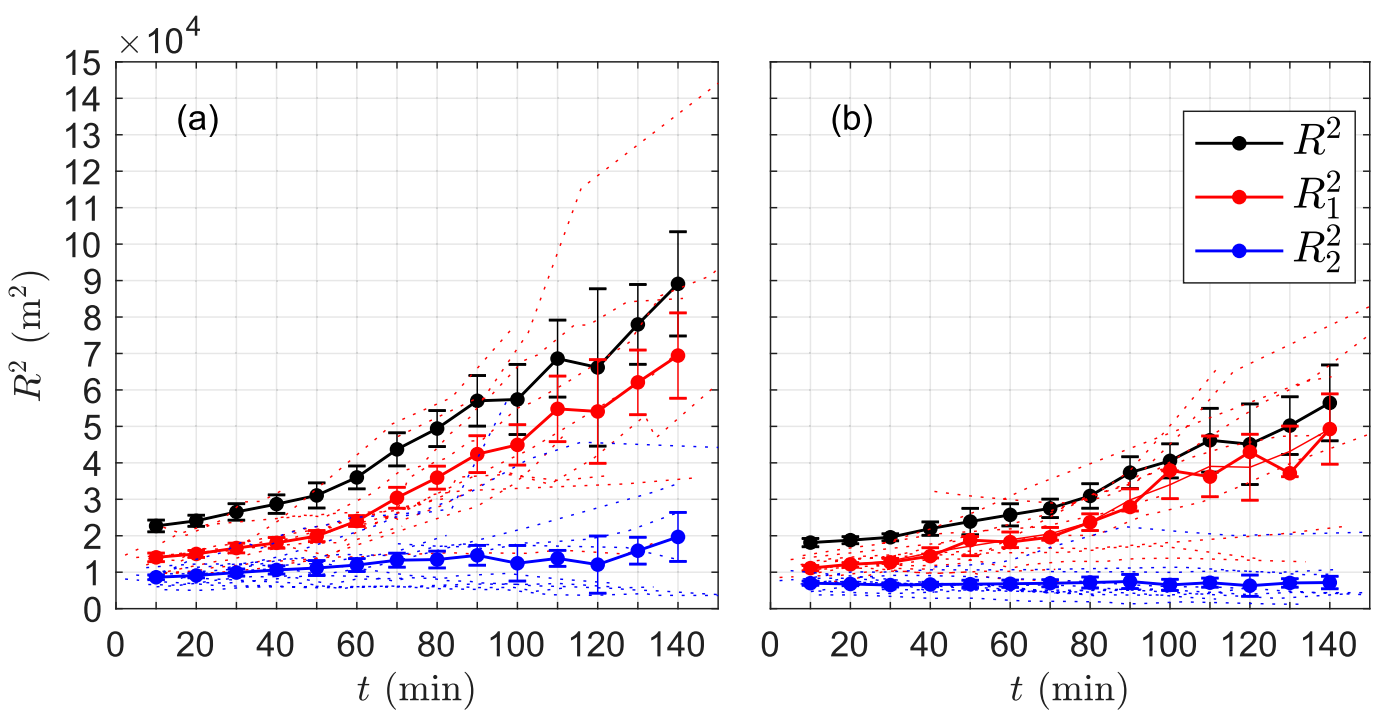

FIG. 5. Relative dispersion (thick lines) computed from (a) all available hyperspectral dye data with initial dye patches of $100 \mathrm{~m}$ and (b) that have corresponding drifter data, which is a total of 13 releases bin averaged every $10 \mathrm{~min}$. This excludes the first (26 May) and last ( 8 June) sampling days. The error bars show the error of the mean (2std $/ \sqrt{N}$, where std is the standard deviation and $N$ is the number of data points within the bin). The principal $\left(R_{1}^{2}\right)$ and perpendicular component $\left(R_{2}^{2}\right)$ are shown with red and blue dots, respectively, and the total $\left(R^{2}=R_{1}^{2}+R_{2}^{2}\right)$ is shown with black dots. The dotted lines show the individual curves used for the bin average.

speed at the peak of the spectrum according to the linear dispersion relationship, is larger than one with largest values on 3 June and 8 June when the winds were the weakest. The offshore wave measurements are roughly in agreement with the local lidar measurements, with the largest differences on 1 June. The turbulent Langmuir number $\mathrm{La}_{t}$ is shown in Fig. $4 \mathrm{~d}$. $\mathrm{La}_{t}$ values are on average around 0.3 , except on 6 June and on $8 \mathrm{June}$ with $\mathrm{La}_{t} \sim 0.4$. On $6 \mathrm{June} \mathrm{La}_{t}$ is larger because of crossing wind sea and swell, which partially cancel the surface Stokes drift and on 8 June due to increasing winds. The value of 0.3 is consistent with wind-wave equilibrium when Langmuir effects are expected to be significant (McWilliams et al. 1997; Sullivan et al. 2004, 2007).

\section{b. Bulk dispersion analysis}

We begin the dispersion analysis by presenting the bulk dispersion statistics of dye and drifters with initial scale of $100 \mathrm{~m}$, and comparing the results. The average dispersion from all dye patches with overlapping drifter data (a total of 13 releases) is shown in Fig. 5a, and the corresponding drifter data is plotted in Fig. 5b. The dispersion from dye is significantly larger than that of drifters. The total average relative diffusivities $\kappa=4.0 \pm 1.1$ and $2.4 \pm 0.6 \mathrm{~m}^{-2} \mathrm{~s}^{-1}$ for the dye and drifter data, respectively. Not only does dispersion between the two tracers differ in magnitude but also in their principal components. The dispersion of the dye is larger both along and perpendicular to the principal component compared to that of the drifters. While $R_{2}^{2}$ from dye gives finite dispersion, that of the drifters remains relatively flat. The differences are likely attributed to vertical shear and background turbulence since the drifters are drogued at a constant depth and integrate horizontal velocity over the depth range of their drogues.

\section{c. Individual realizations}

We proceed to analyze specific cases chronologically, providing a description of the observed dispersion and the underlying ocean processes. The first deployment with dye and drifters was conducted in strong winds with speeds reaching $10 \mathrm{~m} \mathrm{~s}^{-1}$ and challenging wave conditions for the boat $\left(H_{s}=1.5 \mathrm{~m}\right.$ and $\left.T_{p}=7 \mathrm{~s}\right)$. Therefore, only one dye patch was deployed on that day at station 1 . Since the dye deployment scheme was still being sorted out and the currents were strong, unintentionally the dye patch ended up being deployed with an initial scale more than twice that of the group of drifters. Despite the scale mismatch, it is an interesting case since the deployment location was adjacent to a freshwater front which can be seen in the true-color hyperspectral images in Figs. 6a and 6b. The corresponding dye concentration maps and dispersion ellipses are shown in Figs. 6c and 6d, respectively. All the available dispersion ellipses from dye and drifters are shown in Fig. 6e with maroon and orange lines, respectively. The freshwater front quickly deformed the 

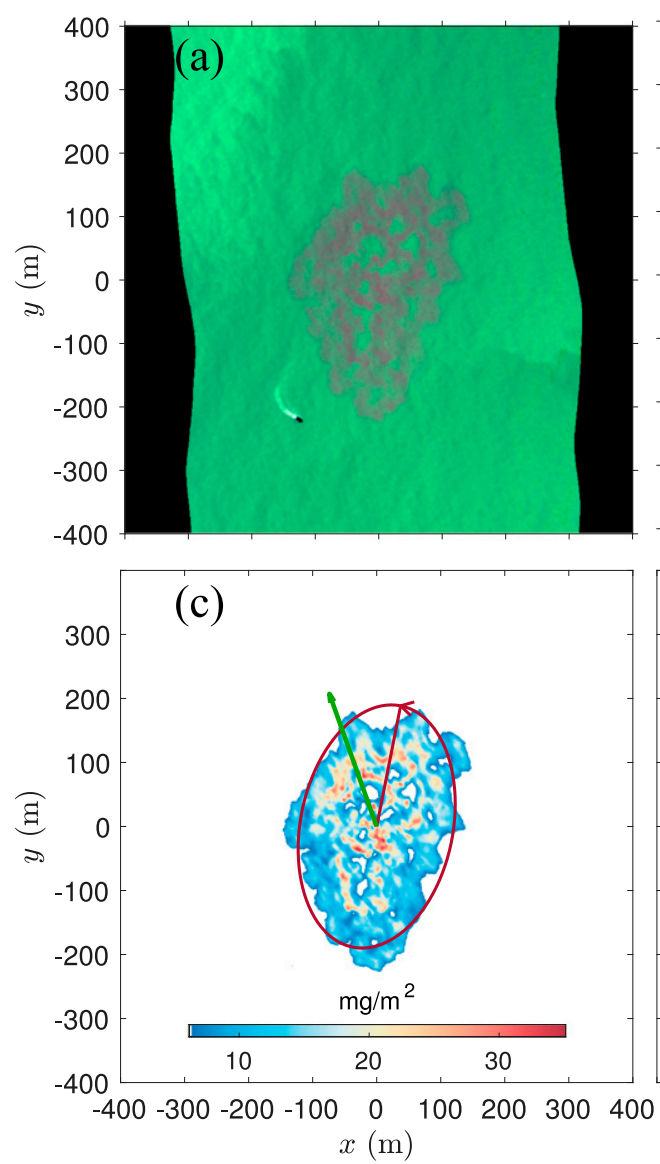

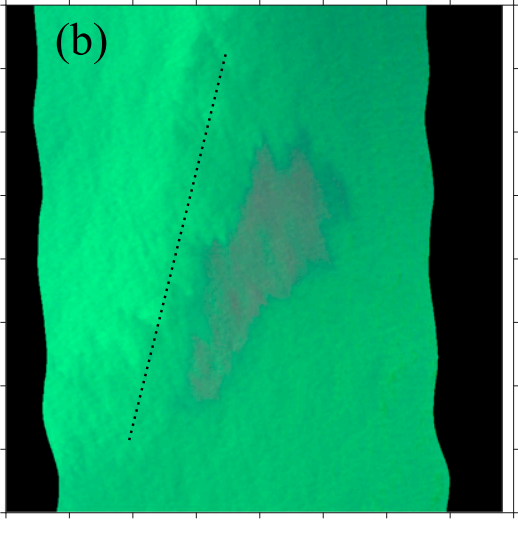

(d)

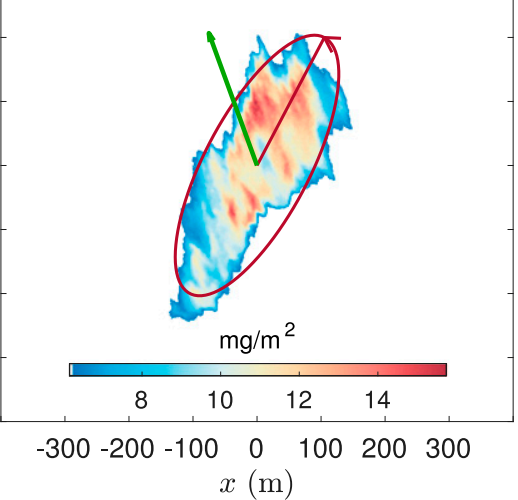

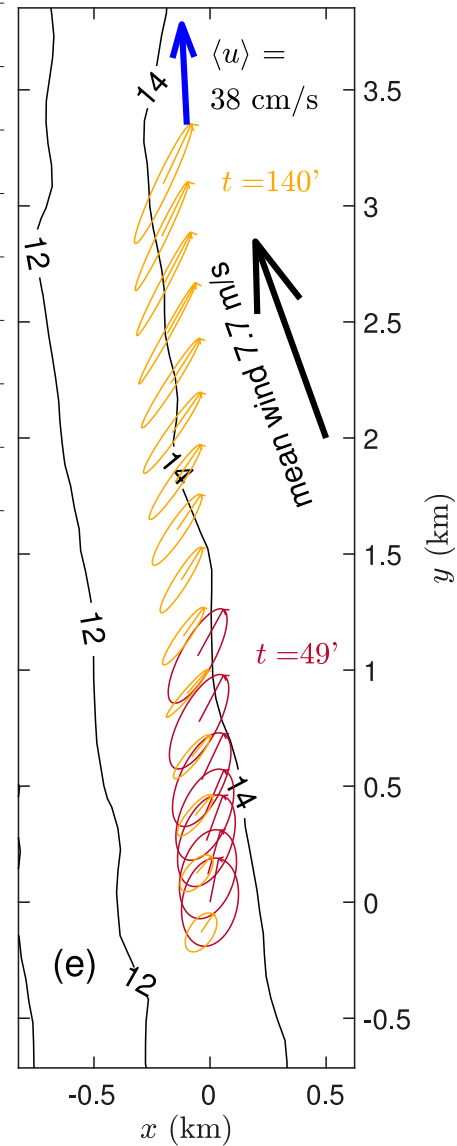

FIG. 6. (a),(b) True-color and (c),(d) dye concentration images of a dye patch deployed near a front after 6 and 38 min, respectively, from the deployment on 26 May 2016. The dye patch gets tilted and stretched along the front and becomes narrower in the cross front. Dye concentration decreases rapidly, practically disappearing $60 \mathrm{~min}$ after deployment. This is consistent with submesoscale frontal dynamics (i.e., surface convergence and strong downwelling at front). The green arrow indicates the surface wind direction. The maroon ellipses show the orientation and root-mean-square width of the dye patch. The black dotted line in (b) qualitatively shows the mean orientation of the front. (e) Complete ellipse series from available dye (maroon) and drifter data (orange) plotted over 12- and 14-m bathymetric contours.

dye patch and group of drifters due to strong surface convergence and horizontal shear typical of submesoscale frontal dynamics (Garvine 1974; O'Donnell et al. 1998; McWilliams et al. 2015; Romero et al. 2016). The dye was quickly advected below the optical depth of the hyperspectral measurements within a period of less than an hour.

The time rate of net mass change from the hyperspectral data can be used to estimate the vertical fluxes and net vertical transport velocity. The dye conservation equation in flux form is given by

$$
\frac{d M}{d t}=\left.F\right|_{z_{d}}+\left.F\right|_{h},
$$

where $M(t)=\iiint C_{V}(t) d x d y d z$ is the total dye mass, and $F$ are the fluxes at the base of the layer observed by the hyperspectral sensor $\left(\left.F\right|_{z_{d}}\right.$, with $\left.z_{d}=1 / K_{\mathrm{em}}\right)$, and the net horizontal fluxes $\left(\left.F\right|_{h}\right)$. Assuming horizontal fluxes are small, Eq. (18) becomes

$$
\frac{d M}{d t}=\iint w C_{V} d x d y \approx w \frac{\bar{M}}{z_{d}}
$$

with

$$
w \approx \frac{\Delta M}{\Delta t} \frac{z_{d}}{\bar{M}}
$$

where $\bar{M}$ is average mass. The vertical velocity estimated from $\Delta M / \Delta t$ obtained with a linear regression and the time averaged mass gives $-66 \pm 14 \mathrm{~m}$ day $^{-1}$. Similarly for a cluster of drifters, the vertical velocity can be estimated through mass conservation integrating the horizontal divergence from the surface to a depth $z_{d}$ according to 


$$
w=\int_{0}^{z_{d}} u_{x}+v_{y} d z
$$

For comparison against the dye observations $z_{d}$ is set equal to $K_{\mathrm{em}}^{-1}$, yielding $w=-52 \pm 13 \mathrm{~m} \mathrm{day}^{-1}$, in agreement the with dye estimates within error bars.

On 29 May field operations were limited due to development of clouds shortly after the dye deployment. Three dye patches were deployed at stations $1-3$, with coincident groups of clusters at stations 1 and 3. All three stations were located near freshwater fronts. In addition to cloud cover, quick vertical advection of dye below a relatively shallow optical depth further limited the availability of remotely sensed dye data. However, the drifters provided good data with significant deformation and convergence at the fronts.

On 31 May the weather allowed for the deployment of dye patches at all four stations. The dispersion ellipses from all the available dye and drifter data are shown in Fig. 7a. The mean surface currents calculated from the drifters are indicated with vectors within insets. The vertical density and dye concentration profiles measured at the center of the dye patches soon after the dye deployment are shown in Figs. $7 \mathrm{~b}$ and $7 \mathrm{c}$, respectively. The dye concentration profiles were smoothed with a fivepoint running mean reducing the step-like structures of the data due to the relatively low sampling frequency of the fluorometer of $1 \mathrm{~Hz}$, compared to the $4 \mathrm{~Hz}$ data for salinity and temperature. The depth of dye penetration is generally consistent with the estimates of the MLD, except for station 1.

The winds on 31 May were to the northwest at $7.2 \mathrm{~m} \mathrm{~s}^{-1}$, partially opposing the surface currents. The mean surface circulation shows a jet-like structure with maxima at station 3 with a speed of $34 \mathrm{~cm} \mathrm{~s}^{-1}$. The dispersion is strongly anisotropic across stations, particularly at station 1 , where the tilting of the dispersion ellipses is qualitatively consistent with that expected from shear dispersion (e.g., Bennett 1987; LaCasce 2008). Station 2 coincided with a front partially aligned with the bathymetry, as determined by the true-color airborne imagery. Consequently, the dye patch at station 2 was stretched along the front and transported below the visible depth of the hyperspectral sensor within less than $2 \mathrm{~h}$ at a rate of $-50 \pm 11 \mathrm{~m} \mathrm{day}^{-1}$.

Dye patches at stations 3 and 4 developed coherent structures consistent with Langmuir circulation (Figs. 8a,b). The dye patch at station 3 measured remotely conserved mass over the sampling period of $2 \mathrm{~h}$ before the data became too noisy due to glitter. The lack of dye mass loss is consistent with the fact that MLD is only slightly deeper than the optical depth of the hyperspectral data. In contrast, the total mass of dye measured remotely at station 4 significantly decreased over a period of $1.5 \mathrm{~h}$ with good quality data before the sun glitter was too strong. The mass loss within layer observed by hyperspectral for that patch $(3.9 \mathrm{~m})$ give a vertical velocity of $55 \pm 10 \mathrm{mday}^{-1}$. In contrast, the drifters do not exhibit a net convergence implying local convergences due to Langmuir circulation acting on the dye at scales shorter the drifter separation (i.e., at the scale of cell widths, roughly $30 \mathrm{~m}$ ).

A three-dimensional composite of the dye measured remotely and in situ with the CTD $110 \mathrm{~min}$ after deployment at station 4 is shown in Fig. 8e. For reference see also 2D image in Fig. 8b showing the location of the CTD casts. The data show a structure qualitatively consistent with that of idealized Langmuir circulation with large concentrations near the surface due to surface convergence and downwelling. Away from the surface convergence regions, the CTD data show the largest dye concentration at a depth near the $\operatorname{MLD}(z \sim-10 \mathrm{~m})$ likely due to transport from divergent regions below surface convergence regions near the MLD.

Another interesting feature is the different spreading directionalities between stations 3 and 4 . The spreading of dye at station 3 is approximately crosswind and so is that of the drifters at station 4. However, the dye at station 4 dispersed preferentially in the mean current direction, suggesting horizontal dispersion of dye due to the action of vertical shear combined with vertical transport by Langmuir circulation. A similar pattern was observed the following day (1 June) when the winds were strong and highly variable at station 1 with weak near surface stratification.

A large storm moved through on the evening of 2 June dropping a large amount of precipitation in a short period. The rain and runoff decreased the density and increased the vertical stratification near the surface and setup a strong cross-shelf density gradient below the MLD (see Fig. 9b). The mean surface currents obtained from the drifters are strong toward the south, reaching $60 \mathrm{~cm} \mathrm{~s}^{-1}$ at stations 3 and 4 (Fig. 9a). The dispersion ellipses are also shown in Fig. 9a. The dye and the drifter ellipses at stations 1 and 2 evolved very similarly, in contrast to the offshore stations where the dye spread is considerable, while that of drifters is weak (station 4) or negative (station 3 ). The mean current vectors suggest that station 3 is located in a convergence zone. The local divergence calculated from the group of drifters is $-2.5 f \pm f$. The collapse of the drifter cluster downcurrent is associated with the convergence of different water masses as suggested by the CTD data. The water density at the location where drifters were recovered is lower than that at the deployment location. The hyperspectral data collected at all four stations indicates that 

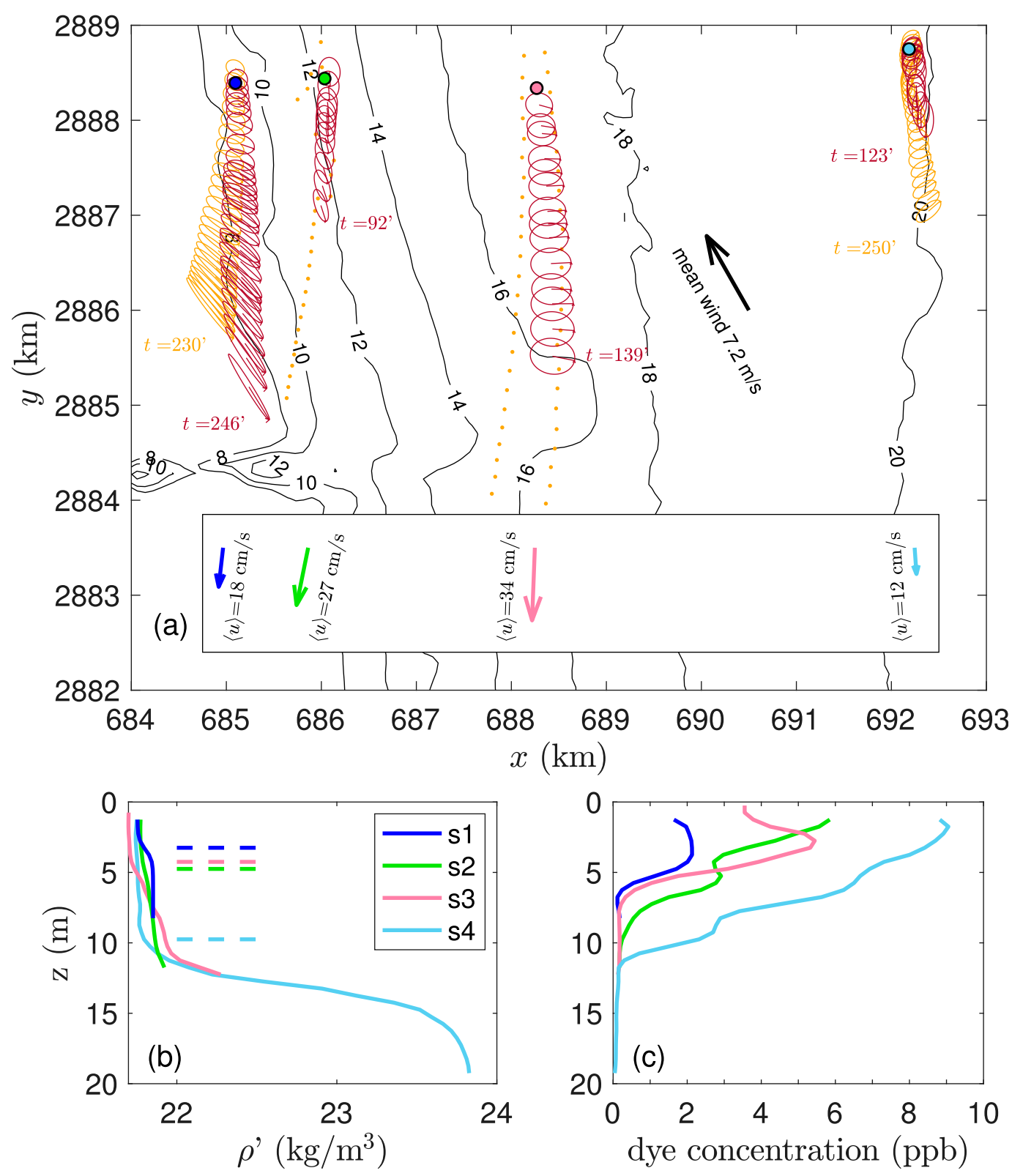

FIG. 7. (a) Dispersion ellipses from available dye (maroon) and drifters (orange) data collected on 31 May plotted over bathymetric contours between 8 and $22 \mathrm{~m}$. The black vector indicates the mean wind. The arrows at the bottom show the mean currents calculated from the drifter trajectories at stations 1-4. (b),(c) CTD density and dye concentration profiles collected within each dye patch (s1-s4) shortly after dye deployment. The CTD sampling locations are shown in (a) with circles. MLD estimates are shown in (b) with horizontal dashed lines.

the strong vertical stratification near the surface prevented the development of Langmuir circulation as can be seen in the relatively smooth dye patches in Figs. $3 \mathrm{c}$ and $3 \mathrm{~d}$ despite the fact that $\mathrm{La}_{t} \approx 0.3$.

The last sampling day with dye patches and drifter clusters with initial scales of $100 \mathrm{~m}$ was conducted on 6 June. The water density had continued to decrease due to rain and runoff, and the winds had reversed to the south-southeast, in favor of the already present cross-shelf density pressure gradient between stations 2 and 4 with lighter water near the coast (Fig. 10c) within the deeper layers of the water column. In contrast, the near-surface density across stations was mixed with lower density near the surface at stations 2 and 3 . The mean Lagrangian surface currents are to the south with significant shear cross-shelf, reaching a maximum speed of $74 \mathrm{~cm} \mathrm{~s}^{-1}$ at station 4 (Fig. 10a), which is the strongest value observed on all sampling days. 

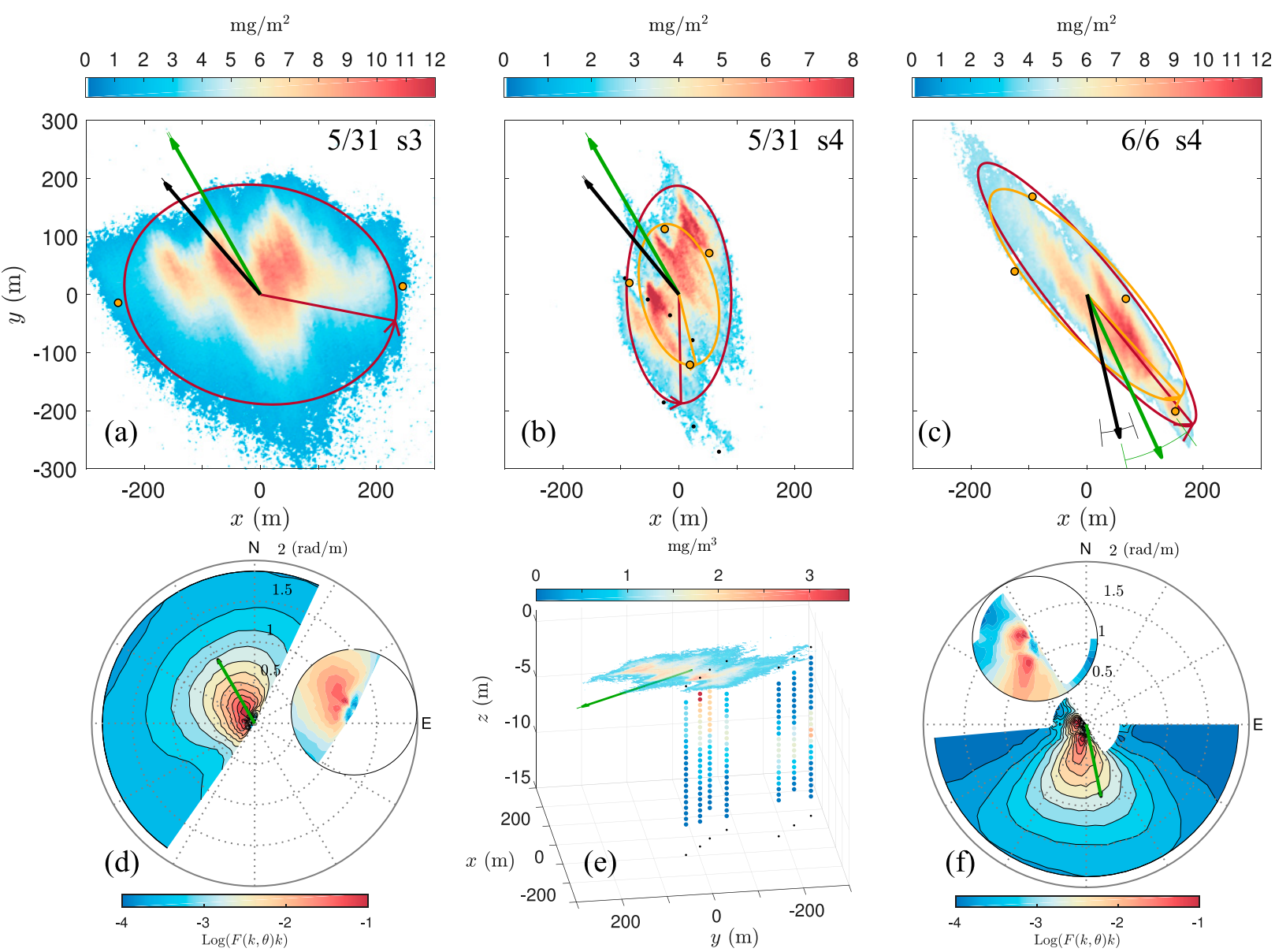

FIG. 8. Dye concentration maps at 138,110, and 182 min from deployment at (a),(b) stations 3 and 4 on 31 May and (c) station 4 on 6 Jun, respectively. Green and black vectors in (a)-(c) show the mean wind direction and expected Langmuir cell alignment according to the law of the wall (Van Roekel et al. 2012), respectively, with variability over the sampling period corresponding to \pm 1 standard deviation. The principal component ellipses are shown in maroon and orange for the dye and drifters, respectively. The drifters are shown with orange circles. Directional wave spectra (energy going toward) for (d) 31 May and (f) 6 Jun. The green arrows in (d) and (f) show the local wind direction. The insets in (d) and (f) are zooms at low wavenumbers showing that in both cases there are two peaks due to wind sea and swell. (e) Three-dimensional composite figure of the remotely sensed dye concentration (rescaled to $\mathrm{mg} \mathrm{m}^{-3}$ through $Z_{C}$ ) and CTD vertical profiles of rhodamine concentration for the map shown in (b) with CTD cast locations shown with black dots.

Clouds moving in and out of the sampling region forced the aircraft to fly at low altitudes during a few tracks which resulted in narrow swaths not sampling the dye patches entirely. Those data were neglected from the analysis. Stations 1 and 2 were near a density front oriented cross-shelf, with station 1 on the dense side and station 2 on the lighter side. The patches quickly reached the front and advected below the optical depth of the hyperspectral measurements at a rate of $20 \pm$ $10 \mathrm{~m} \mathrm{day}^{-1}$ as determined by the rate of change of net mass measured remotely. Both dye patches spread more along the front, but the patch deployed in the side with a lower density, upwind from the front, spread more anisotropically (Fig. 10a). This pattern is also observed in the dispersion ellipses of the drifters with the largest spreading at station 2 overall. The dispersion ellipses at stations 3 and 4 appear to be primarily driven by the strong horizontal shear, with the principal components rotating in the clockwise direction on average of about $45^{\circ}$ during the sampling period.

Although the hyperspectral data from that day show signatures of Langmuir circulation (e.g., Fig. 8c) the dispersion of the dye and drifters across stations do not appear to be strongly influenced by Langmuir circulation, which is consistent with the relatively large turbulent Langmuir number on that day with $\mathrm{La}_{t}=0.4$. The relatively large $\mathrm{La}_{t}$ value is due to mixed locally generated seas and swell from the east, partially canceling the surface Stokes drift and lowering the potential for Langmuir turbulence compared to that from wind-driven shear. The wind wave spectrum for that day is shown in Fig. 8f, with the inset 

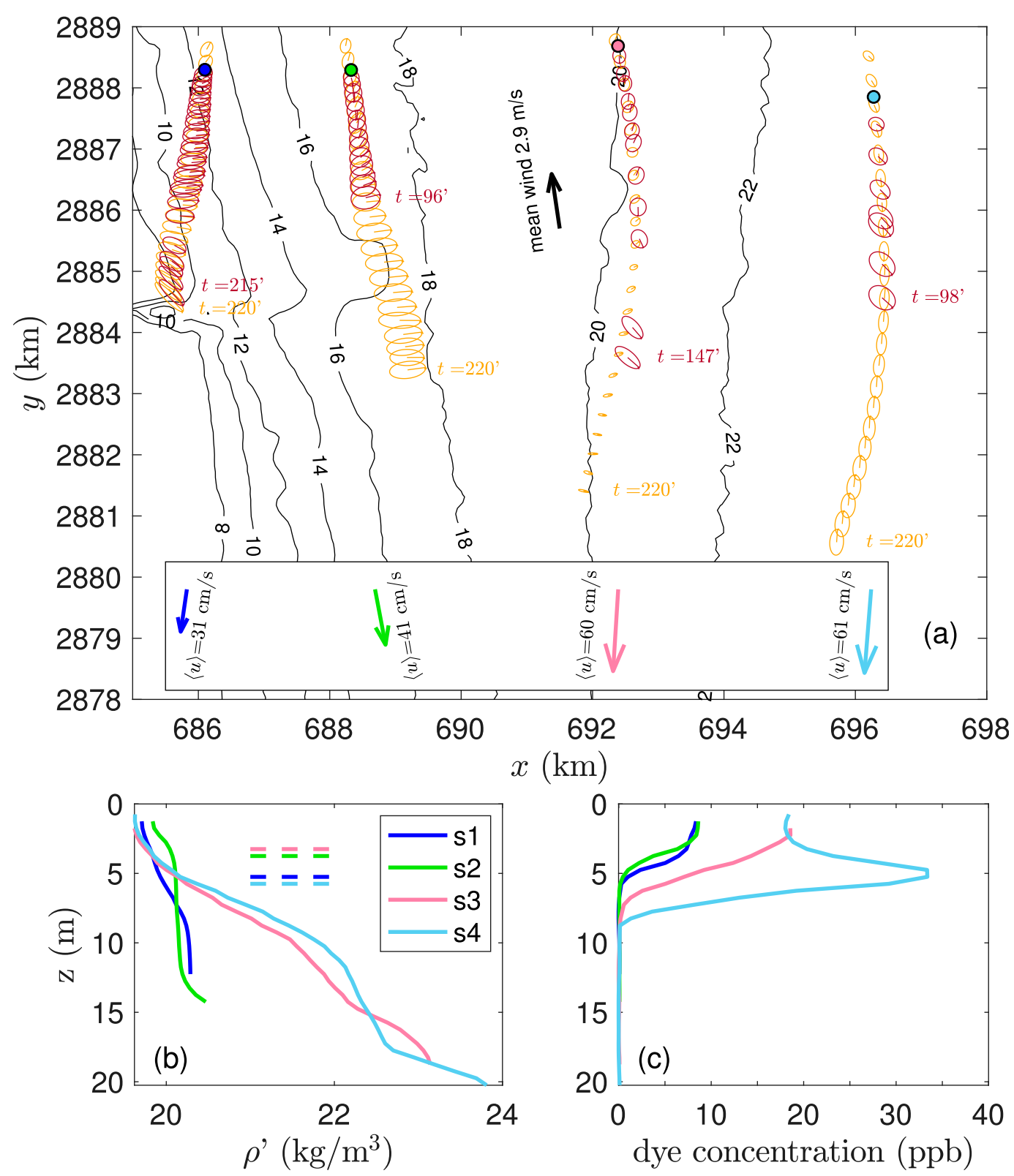

FIG. 9. (a) Dispersion ellipses from available dye (maroon) and drifters (orange) data collected on 3 Jun plotted over bathymetric contours between 8 and $22 \mathrm{~m}$. Stations 2 and 3 were only seeded with 1 and 2 drifters, respectively, which are shown with dots. The black vector indicates the mean wind. The arrows at the bottom show the mean currents calculated from the drifter trajectories at stations 1-4. (b),(c) CTD density and dye concentration profiles collected within each dye patch (s1-s4) shortly after dye deployment. The CTD sampling locations are shown in (a) with circles. MLD estimates are shown in (b) with horizontal dashed lines.

showing the two spectral peaks. In contrast, the wave spectrum from 31 May with lower $\mathrm{La}_{t}$ and similar wind speed also indicates the presence of swell but partially aligned. On that day Langmuir effects appear to play a significant role at stations 3 and 4 as discussed earlier.

This case-by-case analysis shows that the combination of remote sensing and in situ measurements allows identification of the various physical processes acting on the dispersion of tracers. Differences between dispersion from drifters confined to a fixed depth and dye that can move vertically give a sense of how well 3D processes can be inferred from 2D observations. More specifically, we show from direct observations for the first time that Langmuir circulation can drive horizontal dispersion both directly and 

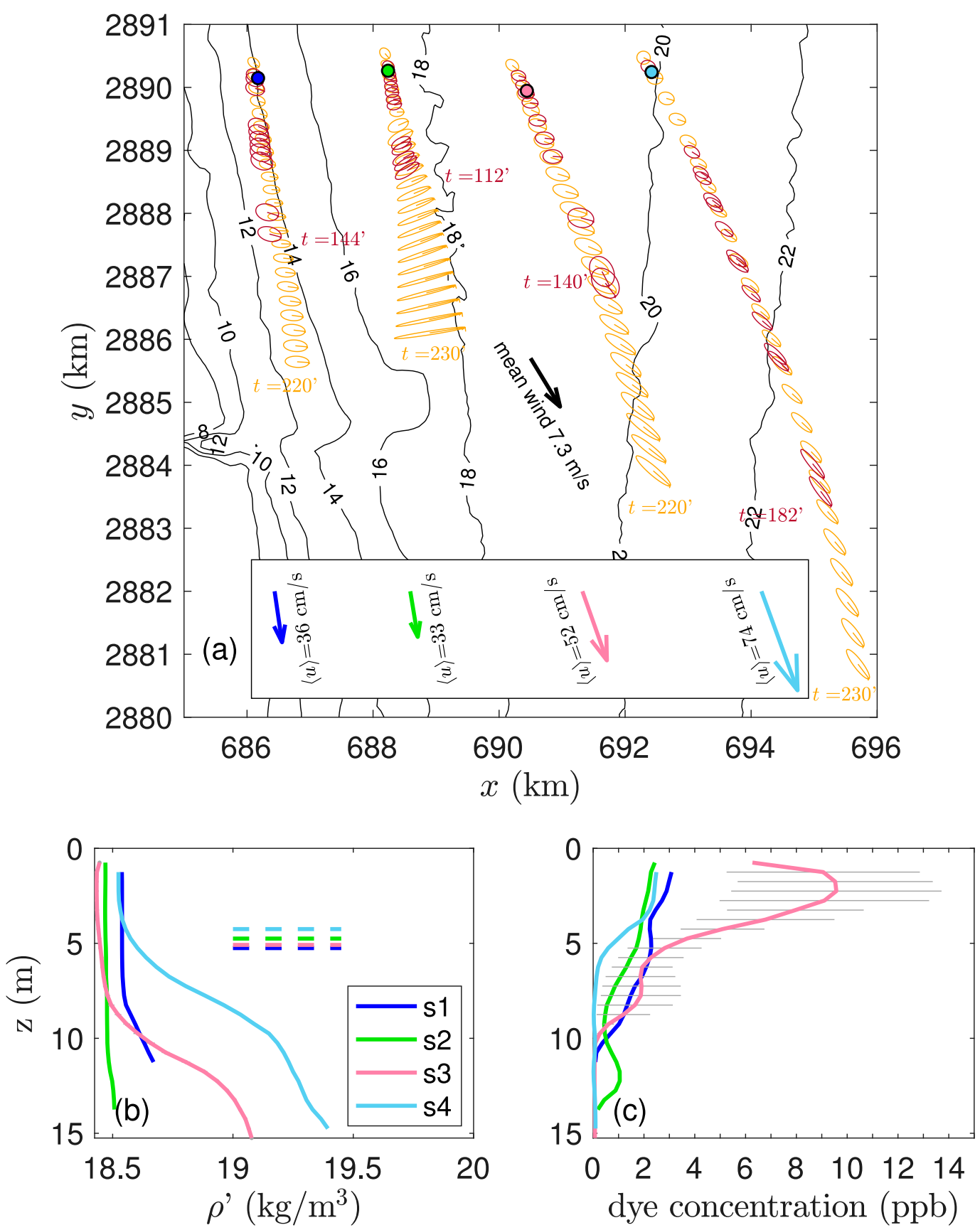

FIG. 10. (a) Dispersion ellipses from available dye (maroon) and drifters (orange) data collected on 6 Jun plotted over bathymetric contours between 8 and $22 \mathrm{~m}$. The black vector indicates the mean wind. The arrows at the bottom show the mean currents calculated from the drifter trajectories at stations 1-4. (b),(c) CTD density and dye concentration profiles collected within each dye patch (s1-s4) shortly after dye deployment. At station 3 the average of three available casts are shown with error bars corresponding to 1 standard deviation. The CTD sampling locations are shown in (a) with circles. MLD estimates are shown in (b) with horizontal dashed lines.

indirectly by moving water vertically for subsequent dispersion by vertical shear in the horizontal currents. Langmuir-driven dispersion can dominate at times and is not captured in drifter observations of dispersion on the scales sampled.

\section{Discussion}

\section{a. Frontal arrest}

The dye and drifter data collected at or near fronts showed the dominance of frontal dynamics on the 

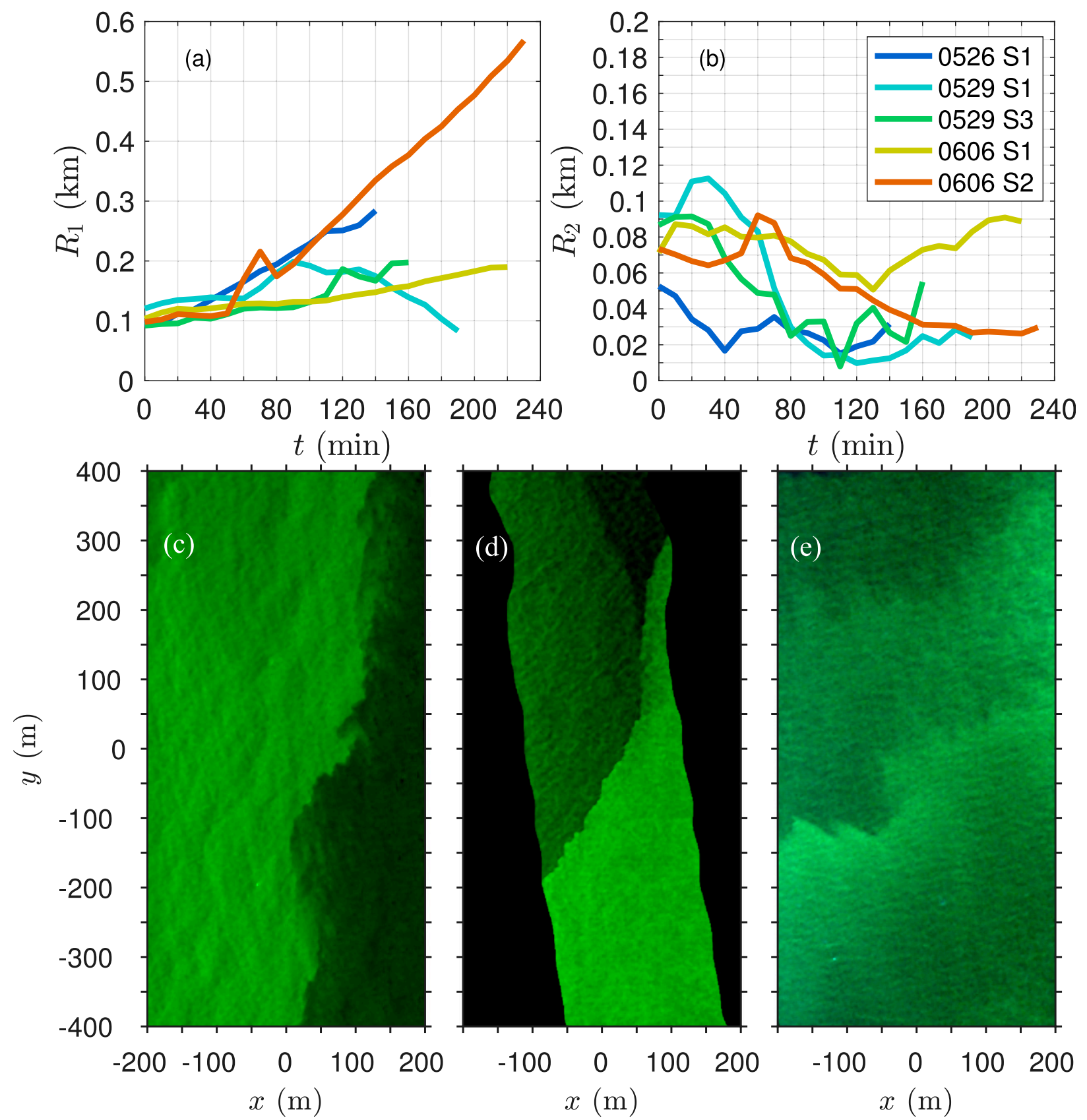

FIG. 11. (a) Principal and (b) off-principal root-mean-square dispersion from drifter data collected near density fronts from deployments on 26 May, 29 May, and 6 Jun as indicated in the legend. True-color hyperspectral images of the corresponding fronts on 26 May (s1), 29 May (s1), and 6 Jun (s2) are shown in (c)-(e), respectively.

dispersion with surface convergence and shear. In light of growing interest on submesoscale frontal dynamics and frontal arrest due to frontal shear instability and/or the lack of relative importance of rotation at small scales contributing to the forward energy cascade (McWilliams 2016; Sullivan and McWilliams 2018), here we analyze the drifter data from deployments near or at fronts as determined from the true-color imagery. The principal and perpendicular root-mean-square drifter dispersion for all data collected near fronts is shown in Figs. 11a and $11 \mathrm{~b}$, respectively. There are a total of five cases: station 1 on 26 May, stations 1 and 3 on 29 May, and stations 1 and 2 on 6 June. The principal component dispersion grows in time, except for station 1 on 26 May. The perpendicular component, or cross-front component, decays asymptoting to scales between 20 and $70 \mathrm{~m}$. 
True-color images at the fronts from those days are shown in Figs. 11c-e. The frontal instabilities as seen in water turbidity range in scale from about 10 to $100 \mathrm{~m}$, qualitatively consistent with the $R_{2}$ asymptotic values of drifter data, suggesting frontal arrest due to frontal instability. This will be further explored elsewhere after gathering additional data required for more robust statistics.

\section{b. Langmuir cells}

The turbulent Langmuir number during the sampling days indicates that Langmuir turbulence is expected to be significant. This is consistent with the fact that streaks and cell-like structure were observed in the hyperspectral dye imagery except on 3 June due to significant near-surface buoyancy inhibiting the development of Langmuir circulation. In cases with well-defined Langmuir cell signatures, it was found that Langmuir cell orientation closely aligned with the wind even in conditions with opposing wind sea and swell (i.e., 6 June; Fig. 8c). This contrasts from previous numerical studies that impose misaligned winds and waves. Van Roekel et al. (2012) investigated Langmuir turbulence under misaligned wind and waves over a wide range of angles. They found good agreement with the "law of the wall," defined as

$$
\tan \left(\alpha_{\mathrm{LOW}}\right)=\frac{\left\langle\partial V_{s}^{\prime} / \partial z\right\rangle_{D_{l}}}{\frac{u_{*}}{k\left|z-D_{l}\right|} \ln \left(\left|D_{l} / z\right|\right)+\left\langle\partial U_{s}^{\prime} / \partial z\right\rangle_{D_{l}}},
$$

where $\alpha_{\text {LOW }}$ is the cell orientation, $\mathbf{U}_{s}^{\prime}(z)$ is the Stokes drift projected along and across the wind direction, $k$ is von Kármán's constant, and the brackets correspond to a vertical average between the surface and a depth $D_{l}$. Van Roekel et al. (2012) found consistent results for $D_{l}=$ MLD or $D_{l}=0.2 \mathrm{MLD}$. Here we use $D_{l}=3 \mathrm{~m}$ for consistency with the estimated mean optical depth of the emission band of rhodamine dye $1 / K_{\mathrm{em}}$ within the MLD.

The cell orientations (Figs. 8a,c) are in good agreement with the law of the wall (Van Roekel et al. 2012), which accounts for the relative orientation of the winddriven shear and the Stokes drift profile. For the case with crossing wind sea and swell (Fig. 8c) the two main cells partially align with the mean wind and the law of the wall, with cell convergence downwind (Farmer and $\mathrm{Li}$ 1995). This is consistent with the fact that the vertical shear of the Stokes drift near the surface is always closely aligned with the wind because the short locally wind-driven waves will be nearly aligned with the wind due to the dynamic coupling between winds and waves. This contrasts with idealized LES simulations of Langmuir turbulence under varying degrees of crossing winds and waves (Van Roekel et al. 2012) that impose the waves as opposed to driving a spectrum of waves under the influence of wind forcing with realistic dynamics. The latter will always have a locally driven wind sea nearly parallel to the wind with a significant contribution to the shear of the Stokes drift downwind near the ocean surface. This shows the importance of incorporating realistic wave forcing for oceanic boundary layer studies of Langmuir circulations (e.g., Sullivan et al. 2012; Large et al. 2019).

\section{c. Scale-dependent diffusivity}

The measurements described here were collected under the influence of various processes including fronts, wind-driven, and coastal shear, and Langmuir circulation, thus providing a robust measure of the overall mean dispersion due to all processes combined at scales of $200 \pm 100 \mathrm{~m}$. To extend the dispersion analysis over a broader range of scales, we further analyzed the dispersion between groups of drifters. The results are shown in Fig. 12 along with the mean values reported earlier for both the dye and drifters. For the sake of comparison, data are plotted over the figure published by Romero et al. (2013) showing results from drifter observations (List et al. 1990; Ohlmann et al. 2012) and numerical simulations in Southern California, over a similar range of scales. There is very good agreement across all datasets at scales of $200 \mathrm{~m}$, with noticeable differences at scales larger than $1 \mathrm{~km}$. There is a qualitative agreement between the observations presented here and the numerical results for headland regions. This is an interesting result since the simulations by Romero et al. (2013) do not explicitly account for Langmuir effects. However, as discussed by Ohlmann et al. (2019), our results differ from Romero et al. (2013) with respect to the directionality of the dispersion with larger observed dispersion cross shelf, which is also on average crosswind. The difference in directionality is likely due to Langmuir turbulence, transient dispersion due to lateral shear for relatively short periods, and fronts not being necessarily parallel to the bathymetry at the scales sampled.

\section{Conclusions}

We presented a novel dataset of Lagrangian observations of horizontal relative dispersion over the inner shelf in South Padre Island, Texas. The novelty of the ISDEX data is in the coincident observations with drifters and dye giving observations of horizontal dispersion at a fixed depth (drifters) and depth integrated near the surface accounting for three-dimensional motion (dye). The observed relative dispersion of dye patches and drifters is similar, with larger and less anisotropic dispersion observed from the dye. The obtained mean 


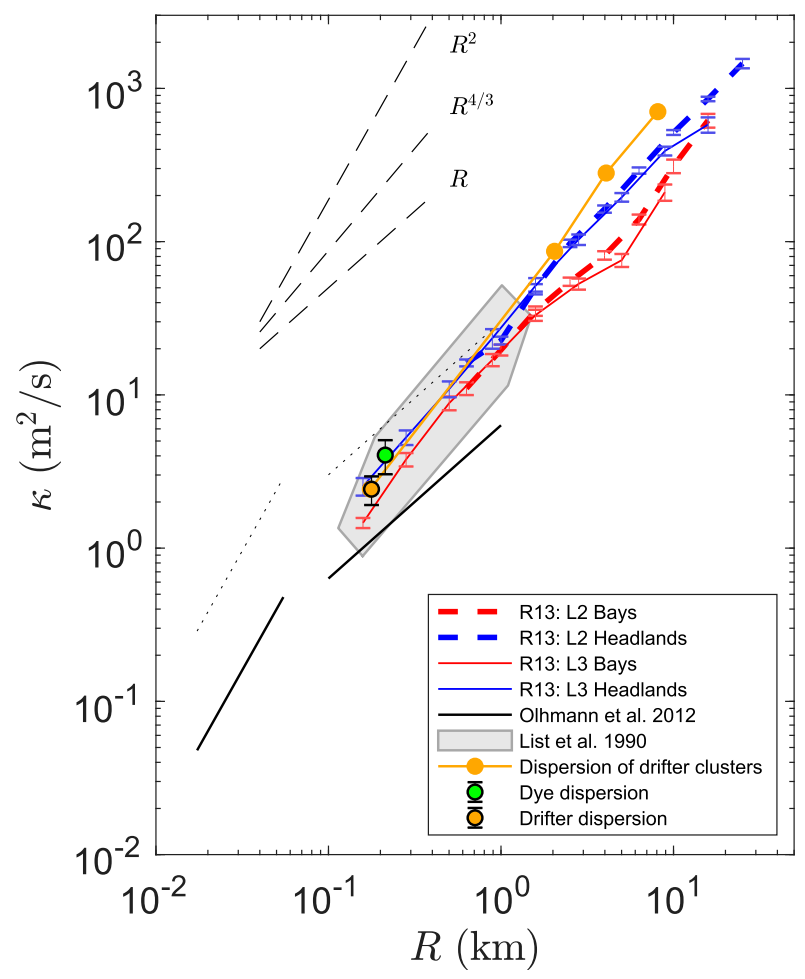

FIG. 12. Relative diffusivity $\kappa$ as a function of scale $R$. Figure modified from Romero et al. (2013) with blue and red lines showing the results of particle-pair dispersion statistics from the ROMS with resolutions of 270 (solid lines) and $75 \mathrm{~m}$ (dashed lines). The black circles with green and orange face colors show the mean dispersion values from the dye and drifters, respectively. The orange circles show the dispersion values calculated between drifter clusters.

relative diffusivity is $\kappa=4.0 \pm 1.1$ and $2.4 \pm 0.6 \mathrm{~m}^{-2} \mathrm{~s}^{-1}$ for the dye patches and clusters of drifters, respectively, at scales of $200 \pm 100 \mathrm{~m}$. The differences highlight the effects due to three-dimensional processes and in particular vertical shear.

The dataset allows characterization of the threedimensional processes controlling the dispersion and evolution of dye patches. Langmuir cells were identified within the dye patches as coherent streaks and cells aligned with the winds on most days. This is consistent with the values of $\mathrm{La}_{t}$ obtained that were generally around 0.3 , implying that Langmuir turbulence was potentially significant. However, no signatures of Langmuir circulation were observed on 3 June when the MLD was shallow and strongly stratified. Dye patches did not always conserve mass, particularly near fronts. Dye patch measurements that did not conserve mass were used to quantify the vertical fluxes and effective vertical transport velocities. We find mean velocities of up to $-66 \mathrm{~m} \mathrm{day}^{-1}$ over horizontal scales of about $200 \mathrm{~m}$, much larger than that expected at mesoscales.
Clusters of drifters deployed near fronts resulted in decreasing cross-front dispersion, asymptoting to rms values ranging between 20 and $70 \mathrm{~m}$, comparable to the scale of frontal instabilities observed in true-color images.

The work shows that many of the relatively smallscale fully three-dimensional ocean processes that transport and mix passive tracers can be identified in comprehensive observational programs of relative dispersion. Specifically the roles of submesoscale fronts and Langmuir turbulence on the observed small-scale relative dispersion are demonstrated. Going forward observations of relative dispersion should continue to be made alongside observations of the underlying physics that cause the dispersion. This will ultimately enable the validation of the physics driving dispersion in numerical models, not just the modeled dispersion values themselves. Future work is planned in the study region to characterize dispersion and the roles of various underlying physics over a wider range of conditions, including tidal jets and eddies, the two main regional wind forcing modes (i.e., downwelling versus upwelling) with data collected during subsequent campaigns.

Acknowledgments. The authors thank Captain (Michael Walker) and crew (Steve Cody) of the F/V Salt Walker for their support; Jessica Madden for her contribution to data collection; and Erik Stassinos, who helped with the dye deployment scheme. We are grateful to the anonymous reviewers whose comments helped to improve the manuscript. L.R. appreciates Erik Fields' guidance with remote sensing processing techniques. Research funded by the National Council of Science and Technology of Mexico-Mexican Ministry of Energy-Hydrocarbon Trust, project 201441. L.R. and J.C.O. acknowledge support from Centro de Investigación Científica y de Educación Superior de Ensenada, Baja California (Grant SB160037). This is a contribution of the Gulf of Mexico Research Consortium (CIGoM).

\section{REFERENCES}

Androulidakis, Y., and Coauthors, 2018: Influence of river-induced fronts on hydrocarbon transport: A multiplatform observational study. J. Geophys. Res. Oceans, 132, 3259-3285, https:// doi.org/10.1029/2017JC013514.

Appendini, C. M., A. Torres-Freyermuth, P. Salles, J. LópezGonzález, and E. T. Mendoza, 2014: Wave climate and trends for the Gulf of Mexico: A 30-yr wave hindcast. J. Climate, 27, 1619-1632, https://doi.org/10.1175/JCLI-D-13-00206.1.

Austin, R. W., and T. J. Petzold, 1986: Spectral dependence of the diffuse attenuation coefficient of light in ocean waters. Opt. Eng., 25, 253471, https://doi.org/10.1117/12.7973845.

Bennett, A. F., 1987: A Lagrangian analysis of turbulent diffusion. Rev. Geophys., 25, 799-822, https://doi.org/10.1029/ RG025i004p00799. 
Beron-Vera, F. J., and J. H. LaCasce, 2016: Statistics of simulated and observed pair separations in the Gulf of Mexico. J. Phys. Oceangr., 46, 2183-2199, https://doi.org/10.1175/JPO-D-15-0127.1.

Berta, M., A. Griffa, T. M. Özgökmen, and A. C. Poje, 2016: Submesoscale evolution of surface drifter triads in the Gulf of Mexico. Geophys. Res. Lett., 43, 11 751-11 759, https://doi.org/ 10.1002/2016GL070357.

Capet, X., J. C. McWilliams, M. J. Molemaker, and A. F. Shchepetkin, 2008a: Mesoscale to submesoscale transition in the California Current System. Part I: Flow structure, eddy flux, and observational tests. J. Phys. Oceanogr., 38, 29-43, https://doi.org/10.1175/2007JPO3671.1.

$[,-,-$, and $\longrightarrow, 2008 \mathrm{~b}$ : Mesoscale to submesoscale transition in the California Current System. Part II: Frontal processes. J. Phys. Oceanogr., 38, 44-64, https://doi.org/ 10.1175/2007JPO3672.1.

,$- \ldots$, , and $-2008 \mathrm{c}$ : Mesoscale to submesoscale transition in the California Current System. Part III: Energy balance and flux. J. Phys. Oceanogr., 38, 2256-2269, https:// doi.org/10.1175/2008JPO3810.1.

Clark, D. B., L. Lenain, F. Feddersen, E. Boss, and R. T. Guza, 2014: Aerial imaging of fluorescent dye in the near shore. J. Atmos. Oceanic Technol., 31, 1410-1421, https://doi.org/ 10.1175/JTECH-D-13-00230.1.

Craik, A. D. D., and S. Leibovich, 1976: A rational model for Langmuir circulations. J. Fluid Mech., 73, 401-426, https:// doi.org/10.1017/S0022112076001420.

D'Asaro, E. A., and Coauthors, 2018: Ocean convergence and the dispersion of flotsam. Proc. Natl. Acad. Sci. USA, 115, 1162 1167, https://doi.org/10.1073/pnas.1718453115.

Emery, W. J., and R. E. Thomson, 2001: Data Analysis Methods in Physical Oceanography. Elsevier Science, $654 \mathrm{pp}$.

Farmer, D., and M. Li, 1995: Patterns of bubble clouds organized by Langmuir circulation. J. Phys. Oceanogr., 25, 1426-1440, https:// doi.org/10.1175/1520-0485(1995)025<1426:POBCOB > 2.0.CO;2.

Garvine, R. W., 1974: Dynamics of small-scale oceanic fronts J. Phys. Oceanogr., 4, 557-569, https://doi.org/10.1175/15200485(1974)004<0557:DOSSOF $>2.0 . C O ; 2$.

Hedley, J. D., A. R. Harborne, and P. J. Mumby, 2005: Simple and robust removal of sun glint for mapping shallow-water benthos. Int. J. Remote Sens., 26, 2107-2112, https://doi.org/ 10.1080/01431160500034086.

Huang, P. Q., Y. Z. Lu, and S. Q. Zhou, 2018: An objective method for determining ocean mixed layer depth with applications to WOCE data. J. Atmos. Oceanic Technol., 35, 441-458, https:// doi.org/10.1175/JTECH-D-17-0104.1.

Kenyon, K. E., 1970: Stokes transport. J. Geophys. Res., 75, 11331135, https://doi.org/10.1029/JC075i006p01133.

LaCasce, J. H., 2008: Statistics from Lagrangian observations. Prog. Oceanogr., 77, 1-29, https://doi.org/10.1016/j.pocean.2008.02.002.

- , and C. Ohlmann, 2003: Relative dispersion at the surface of the Gulf of Mexico. J. Mar. Res., 61, 285-312, https://doi.org/ 10.1357/002224003322201205.

Large, W. G., and S. Pond, 1982: Sensible and latent heat flux measurements over the ocean. J. Phys. Oceanogr., 12, 464-482, https:// doi.org/10.1175/1520-0485(1982)012<0464:SALHFM>2.0.CO;2.

_ - E. G. Patton, A. K. DuVivier, P. P. Sullivan, and L. Romero, 2019: Similarity theory in the surface layer of large-eddy simulations of the wind, wave and buoyancy forced Southern Ocean. J. Phys. Oceanogr., 49, 2165-2187, https://doi.org/10.1175/ JPO-D-18-0066.1.

Liang, J.-H., X. Wan, K. A. Rose, P. P. Sullivan, and J. C. McWilliams, 2018: Horizontal dispersion of buoyant materials in the ocean surface boundary layer. J. Phys. Oceanogr., 48, 2103-2125, https://doi.org/10.1175/JPO-D-18-0020.1.

List, E. J., G. Gartrell, and C. D. Winant, 1990: Diffusion and dispersion in coastal waters. J. Hydraul. Eng., 116, 1158-1179, https://doi.org/10.1061/(ASCE)0733-9429(1990)116:10(1158).

McWilliams, J. C., 2016: Submesoscale currents in the ocean. Proc. Roy. Soc. London., 472, 20160117, https://doi.org/ 10.1098/rspa.2016.0117.

_ P. P. Sullivan, and C.-H. Moeng, 1997: Langmuir turbulence in the ocean. J. Fluid Mech., 334, 1-30, https://doi.org/10.1017/ S0022112096004375.

—_, J. M. Restrepo, and E. M. Lane, 2004: An asymptotic theory for the interaction of waves and currents in coastal waters. J. Fluid Mech., 511, 135-178, https://doi.org/10.1017/ S0022112004009358.

_ J J. Gula, M. J. Molemaker, L. Renault, and A. F. Shchepetkin, 2015: Filament frontogenesis by boundary layer turbulence. J. Phys. Oceanogr., 45, 1988-2005, https://doi.org/10.1175/ JPO-D-14-0211.1.

Melville, W. K., L. Lenain, D. R. Cayan, M. Kahru, J. P. Kleissl, P. Linden, and N. M. Statom, 2016: The Modular Aerial Sensing System. J. Atmos. Oceanic Technol., 33, 1169-1184, https://doi.org/10.1175/JTECH-D-15-0067.1.

Mensa, J. A., T. M. Özgökmen, A. C. Poje, and J. Imberger, 2015: Material transport in a convective surface mixed layer under weak wind forcing. Ocean Modell., 96, 226-242, https:// doi.org/10.1016/j.ocemod.2015.10.006.

Moeller, C. C., O. K. Huh, H. H. Roberts, L. E. Gumley, and W. P. Menzel, 1993: Response of Louisiana coastal environments to a cold front passage. J. Coastal Res., 9, 434-447, https:// www.jstor.org/stable/4298101.

Molinari, R., and A. D. Kirwan, 1975: Calculations of differential kinematic properties from Lagrangian observations in the western Caribbean Sea. J. Phys. Oceanogr., 5, 483-491, https://doi.org/10.1175/1520-0485(1975)005<0483: CODKPF $>2.0 . \mathrm{CO} ; 2$.

Mueller, J. L., 2000: SeaWiFS algorithm for the diffuse attenuation coefficient, K(490), using water-leaving radiances at 490 and $555 \mathrm{~nm}$. SeaWiFS Postlaunch Calibration and Validation Analyses, Part 3, S. B. Hooker and E. R. Firestone, Eds., NASA/TM-2000-206892, Vol. 11, 24-27, https:/oceancolor.gsfc.nasa.gov/SeaWiFS/TECH_REPORTS/ PLVol11.pdf.

Niiler, P. P., A. S. Sybrandy, K. Bi, P. M. Poulain, and D. Bitterman, 1995: Measurements of the water-following capability of holey-sock and TRISTAR drifters. Deep-Sea Res. I, 42, https://doi.org/10.1016/0967-0637(95)00076-3.

O’Donnell, J., G. O. Marmorino, and L. T. Clifford, 1998: Convergence and downwelling at a river plume front. J. Phys. Oceanogr., 28, 1481-1495, https://doi.org/10.1175/1520-0485(1998) 028<1481:CADAAR $>2.0$. CO; 2

Ohlmann, J. C., P. F. White, A. L. Sybrandy, and P. P. Niiler, 2005: GPS-cellular drifter technology for coastal ocean observing systems. J. Atmos. Oceanic Technol., 22, 1381-1388, https:// doi.org/10.1175/JTECH1786.1.

, J. H. LaCasce, L. Washburn, A. J. Mariano, and B. Emery, 2012: Relative dispersion observations and trajectory modeling in the Santa Barbara Channel. J. Geophys. Res., 117, C05040, https://doi.org/10.1029/2011JC007810.

-, M. J. Molemaker, B. Baschek, B. Holt, G. Marmorino, and G. Smith, 2017: Drifter observations of submesoscale flow kinematics in the coastal ocean. Geophys. Res. Lett., 44, 330-337, https://doi.org/10.1002/2016GL071537. 
_ L. Romero, E. Pallàs-Sanz, and P. Perez-Brunius, 2019: Anisotropy in coastal ocean relative dispersion observations. Geophys. Res. Lett., 46, 879-888, https://doi.org/10.1029/2018GL081186.

Okubo, A., and C. C. Ebbesmeyer, 1976: Determination of vorticity, divergence, and deformation rates from analysis of drogue observations. Deep-Sea Res., 23, 349-352, https:// doi.org/10.1016/0011-7471(76)90875-5.

Poje, A. C., A. C. Haza, T. M. Özgökmen, M. G. Magaldi, and Z. D. Garraffo, 2010: Resolution dependent relative dispersion statistics in a hierarchy of ocean models. Ocean Modell., 31, 36-50, https://doi.org/10.1016/j.ocemod.2009.09.002.

—_ and Coauthors, 2014: Submesoscale dispersion in the vicinity of the Deepwater Horizon spill. Proc. Natl. Acad. Sci. USA, 111, 12 693-12 698, https://doi.org/10.1073/pnas.1402452111.

Romero, L., and W. K. Melville, 2010: Airborne observations of fetch-limited waves in the Gulf of Tehuantepec. J. Phys. Oceanogr., 40, 441-465, https://doi.org/10.1175/2009JPO4127.1.

,-- , and J. M. Kleiss, 2012: Spectral energy dissipation due to surface-wave breaking. J. Phys. Oceanogr., 42, 1421-1444, https://doi.org/10.1175/JPO-D-11-072.1.

_ , Y. Uchiyama, J. C. Ohlmann, J. C. McWilliams, and D. A. Siegel, 2013: Simulations of nearshore particle-pair dispersion in Southern California. J. Phys. Oceanogr., 43, 1862-1879, https://doi.org/10.1175/JPO-D-13-011.1.

- D. A. Siegel, J. C. McWilliams, Y. Uchiyama, and C. Jones, 2016: Characterizing stormwater dispersion and dilution from small coastal streams. J. Geophys. Res. Oceans, 121, 39263943, https://doi.org/10.1002/2015JC011323.

, L. Lenain, and W. K. Melville, 2017: Observations of surfacewave-current interaction. J. Phys. Oceanogr., 47, 615-632, https://doi.org/10.1175/JPO-D-16-0108.1.
Sea-Bird, 2017: Seasoft V2: SBE data processing CTD data processing \& plotting software for Windows. Sea-Bird Scientific, 177 pp.

Sullivan, P. P., and J. C. McWilliams, 2018: Frontogenesis and frontal arrest of a dense filament in the oceanic surface boundary layer. J. Fluid Mech., 837, 341-380, https://doi.org/ 10.1017/jfm.2017.833.

, and W. K. Melville, 2004: The oceanic boundary layer driven by wave breaking with stochastic variability. Part 1 . Direct numerical simulations. J. Fluid Mech., 507, 143-174, https://doi.org/10.1017/S0022112004008882.

,$- \ldots$, and — 2007: Surface gravity wave effects in the oceanic boundary layer: Large-eddy simulation with vortex force and stochastic breakers. J. Fluid Mech., 593, 405-452, https://doi.org/10.1017/S002211200700897X.

_ L. Romero, J. C. McWilliams, and W. K. Melville, 2012: Transient evolution of Langmuir Turbulence in ocean boundary layers driven by hurricane winds and waves. J. Phys. Oceanogr., 42, 1959-1980, https://doi.org/10.1175/JPO-D-12-025.1.

Van Roekel, L. P., B. Fox-Kemper, P. P. Sullivan, P. E. Hamlington, and S. R. Haney, 2012: The form and orientation of Langmuir cells for misaligned winds and waves. J. Geophys. Res. 117, C05001, https://doi.org/10.1029/2011JC007516.

Whilden, K. A., S. A. Socolofsky, K. A. Chang, and J. L. Irish, 2014: Using surface drifter observations to measure tidal vortices and relative diffusion at Aransas Pass, Texas. Environ. Fluid Mech., 14, 1147-1172, https://doi.org/10.1007/ s10652-014-9361-4.

Wilson, J. F., Jr., E. D. Cobb, and F. A. Kilpatrick, 1968: Fluorometric producers for dye tracing. USGS Open-File Rep. 84234, 53 pp., https://pubs.usgs.gov/of/1984/0234/report.pdf. 